\title{
Intracellular and Trans-Synaptic Regulation of Glutamatergic Synaptogenesis by EphB Receptors
}

\author{
Matthew S. Kayser, Andrew C. McClelland, Ethan G. Hughes, and Matthew B. Dalva \\ Department of Neuroscience, University of Pennsylvania School of Medicine, Philadelphia, Pennsylvania 19104
}

\begin{abstract}
The majority of mature excitatory synapses in the CNS are found on dendritic spines and contain AMPA- and NMDA-type glutamate receptors apposed to presynaptic specializations. EphB receptor tyrosine kinase signaling has been implicated in both NMDA-type glutamate receptor clustering and dendritic spine formation, but it remains unclear whether EphB plays a broader role in presynaptic and postsynaptic development. Here, we find that EphB2 is involved in organizing excitatory synapses through the independent activities of particular EphB2 protein domains. We demonstrate that EphB2 controls AMPA-type glutamate receptor localization through PDZ (postsynaptic density-95/Discs large/zona occludens-1) binding domain interactions and triggers presynaptic differentiation via its ephrin binding domain. Knockdown of EphB2 in dissociated neurons results in decreased functional synaptic inputs, spines, and presynaptic specializations. Mice lacking EphB1-EphB3 have reduced numbers of synapses, and defects are rescued with postnatal reexpression of $\mathrm{EphB} 2$ in single neurons in brain slice. These results demonstrate that EphB2 acts to control the organization of specific classes of mature glutamatergic synapses.
\end{abstract}

Key words: Eph; ephrin; synaptogenesis; AMPA; spine; trans-synaptic

\section{Introduction}

During early development, neurons undergo a period of synaptogenesis, followed by maturation of these connections. A number of molecular signals control aspects of synapse development, ranging from secreted factors that affect the competence of neurons to make synapses, to cell-cell adhesion proteins that locally drive the organization or maturation of synaptic specializations (Li and Sheng, 2003; Scheiffele, 2003; Craig et al., 2006; Kayser and Dalva, 2006). Trans-synaptic interactions involving EphBephrinB, neurexin-neuroligin, synaptic cell adhesion molecule (SynCAM), cadherins, SALM2 (synaptic adhesion-like molecule 2 ), and netrin-G2 ligand (NGL-2) are potential regulators of these cell-contact-mediated events (Scheiffele, 2003; Washbourne et al., 2004; Kim et al., 2006; Ko et al., 2006), although no individual signal appears to control the formation of all synaptic inputs or all components of each mature synapse. EphB is an attractive candidate synaptogenic molecule because it contains multiple signaling and protein interaction domains; however, its role in excitatory synapse development beyond dendritic spine formation and NMDA receptor (NMDAR) clustering is not known.

Ephs are expressed in the developing and mature nervous

Received May 18, 2006; revised 0ct. 13, 2006; accepted 0ct. 13, 2006.

This work was supported by National Institutes of Health Ruth L. Kirschstein National Research Service Award NS051894-01 (M.S.K.) and by the Whitehall Foundation, Philadelphia Foundation/Mental Retardation and Developmental Disability Research Center Grant HD-026979-0, and Edward Mallinckrodt, Jr. Foundation (M.B.D.). We thank M. Henkemeyer for the gift of EphB1-EphB3 knock-out mice, M. Maronski and J. Zhu for technical assistance, and R. Balice-Gordon, G. Bashaw, P. Haydon, J. Raper, and J. Pablo Labrador for helpful discussions.

Correspondence should be addressed to Matthew B. Dalva, University of Pennsylvania, 1127 BRB II/III, 421 Curie Boulevard, Philadelphia, PA 19104. E-mail: dalva@mail.med.upenn.edu

DOI:10.1523/JNEUROSCI.3072-06.2006

Copyright $\odot 2006$ Society for Neuroscience $\quad$ 0270-6474/06/2612152-13\$15.00/0 system, with classic functions mediating axon guidance and target recognition (Flanagan and Vanderhaeghen, 1998). In vitro, activation of EphB by a soluble ephrinB induces EphB kinasedependent formation of dendritic spines (Ethell et al., 2001; Penzes et al., 2003). Hippocampal neurons in vitro from animals lacking the EphB subtypes expressed in brain, EphB1-EphB3, have few mature spines; in vivo, spine density and size are reduced (Henkemeyer et al., 2003). EphrinB binding to EphB also induces a direct extracellular interaction between EphB and NMDARs (Dalva et al., 2000), resulting in NMDAR clustering and enhanced NMDAR-dependent $\mathrm{Ca}^{2+}$ flux (Takasu et al., 2002). Animals lacking EphB2 display abnormal NMDAR-dependent synaptic plasticity and a $40 \%$ reduction in synapse-associated NMDARs (Grunwald et al., 2001; Henderson et al., 2001). Neurons from $E p h B 1^{-1-}, 2^{-\prime-}, 3^{-\prime-}$ mice have few dendritic NMDAR clusters; unexpectedly, these neurons have reduced AMPA receptor (AMPAR) density as well (Henkemeyer et al., 2003), raising the possibility that EphB is more broadly involved in postsynaptic differentiation.

EphB signaling has also been implicated in presynaptic differentiation. EphrinB treatment increases the density of synaptic release sites (Dalva et al., 2000) and of presynaptic markers apposed to spines (Penzes et al., 2003). It is not known whether these effects are attributable to local trans-synaptic EphB-ephrinB interactions or are secondary to EphB-induced changes in postsynaptic morphology or cell-wide maturation.

EM examination of synapses in hippocampus of mature animals lacking EphB1-EphB3 has revealed decreased size of the postsynaptic density in addition to dendritic spine abnormalities (Henkemeyer et al., 2003). However, whether there is an overall reduction in synapse number in $E p h B 1^{-/-}, 2^{-/-}, 3^{-/-}$mice and whether these irregularities reflect more general developmental 
defects remains unclear. We report that EphB regulates the formation of functional excitatory synaptic contacts between neurons. Along with work indicating that EphB mediates the morphologic maturation of dendrites (Ethell et al., 2001; Henkemeyer et al., 2003; Penzes et al., 2003; Hoogenraad et al., 2005), our data suggests that trans-synaptic EphB-ephrinB signaling can direct the fundamental repertoire of events during glutamatergic synapse development: NMDA and AMPA receptor clustering, dendritic spine formation, and presynaptic terminal differentiation.

\section{Materials and Methods}

\section{Cortical neuronal culture and slice culture}

Dissociated cortical neurons were prepared from embryonic day 17 (E17) to E18 rats and cultured in Neurobasal (Invitrogen, Carlsbad, CA), B27 supplement (Invitrogen), glutamine (Sigma, St. Louis, MO), and penicillin-streptomycin (Sigma) on poly-D-lysine (Sigma) and laminin (BD Biosciences, San Jose, CA) coated glass coverslips (12 mm; Bellco Glass, Vineland, NJ) in 24-well plates. Cells were cultured at 50,000/well for ephrinB2 treatment coclustering assays and 150,000/well for transfection experiments and were maintained in a humidified incubator with $5 \% \mathrm{CO}_{2}$ at $37^{\circ} \mathrm{C}$. For cortical brain slices, $300 \mu \mathrm{m}$ slices (Vibratome; Warner Instruments, Hamden, CT) were made from postnatal day 4 (P4) to P6 mice and placed in $0.4 \mu \mathrm{m}$ Millicell Culture Inserts (Millipore, Bedford, MA) in six-well plates. Slices were maintained in a humidified incubator with $5 \% \mathrm{CO}_{2}$ at $37^{\circ} \mathrm{C}$ in $1 \mathrm{ml}$ of stock solution medium containing $50 \mathrm{ml}$ of Neurobasal and supplements, $25 \mathrm{ml}$ of HBSS, $25 \mathrm{ml}$ of horse serum, $0.65 \mathrm{~g}$ of dextrose, $1 \mathrm{ml}$ of $1 \mathrm{M}$ HEPES, and $1 \mathrm{ml}$ of penicillin-streptomycin, at $\mathrm{pH}$ 7.2-7.3. EphB1 $1^{-1-}, 2^{-1-}, 3^{-1-}$ and $E \mathrm{phB1} 1^{-1-}, 3^{-1-}$ mice were generated and outcrossed into a CD1 background by Dr. Mark Henkemeyer (University of Texas Southwestern Medical Center, Dallas, TX) (Henkemeyer et al., 2003).

\section{Antibodies and reagents}

The following antibodies were used: monoclonal $\alpha$ NR1 (1:150; BD PharMingen, San Diego, CA), $\alpha$-glutamate receptor subunit 2 ( $\alpha$ GluR2) (1:250; Chemicon, Temecula, CA), $\alpha$ synaptic vesicle protein 2 ( $\alpha$ SV2) (1:200; Developmental Studies Hybridoma Bank, University of Iowa, Iowa City, IA), $\alpha \mathrm{M} 2$ FLAG (1:5000; Sigma), and $\alpha$ postsynaptic density-95 ( $\alpha$ PSD-95) (1:200; Affinity BioReagents, Golden, CO); rabbit polyclonal $\alpha$ NR2B (1:1500) (Takasu et al., 2002), $\alpha$ GluR2,3 (1:1000; Chemicon), $\alpha$ FLAG (1:4000; Sigma), $\alpha$ EphB2 (1:1000) (Dalva et al., 2000), $\alpha$ synaptic ras-GTPase-activating protein ( $\alpha$ SynGAP) (1:1000; Affinity BioReagents), and $\alpha$-tau (gift from Dr. V. Lee, University of Pennsylvania School of Medicine, Philadelphia, PA), and $\alpha$ EphrinB3 (1:50; Zymed, San Francisco, CA); goat polyclonal $\alpha$ EphrinB1 and $\alpha$ EphrinB3 (1:500; R \& D Systems, Minneapolis, MN); guinea pig polyclonal $\alpha$ vesicular glutamate transporter ( $\alpha$ VGLUT1) (1:5000; Chemicon); chicken polyclonal $\alpha$ green fluorescent protein ( $\alpha \mathrm{GFP})$ (1:2500; Chemicon); and ephrinB2-Fc (1:200). Cyanine 2, 3, and 5 secondary antibodies were obtained from Jackson ImmunoResearch and used at 1:250 to 1:700. EphrinB2-Fc and Fc control were preclustered with antihuman Fc antibody at $50 \mathrm{ng} / \mathrm{ml}$ in Neurobasal media at room temperature for $30 \mathrm{~min}$ and applied at $500 \mathrm{ng} / \mathrm{ml}$ to stimulate neurons. APV (Sigma) was used at $100 \mu \mathrm{M}$.

\section{Immunocytochemistry}

Dissociated cortical neurons were fixed in 50\% methanol/50\% acetone for $2 \mathrm{~min}$ at $-20^{\circ} \mathrm{C}$ or $4 \%$ paraformaldehyde (PFA) $/ 2 \%$ sucrose in $\mathrm{PBS}$ for $8 \mathrm{~min}$ at room temperature. Neurons were then washed three times for 5 min each in PBS and blocked (5-10\% BSA in PBS) for $2 \mathrm{~h}$ at room temperature. For permeabilizing conditions, $0.1 \%$ Triton X-100 was added to block. Brains from transgenic animals were immersion fixed in $10 \%$ trichloroacetic acid for $1 \mathrm{~h}$ at room temperature, washed three times for $5 \mathrm{~min}$ each in $30 \mathrm{~mm}$ glycine PBS, and sunk in 30\% sucrose PBS overnight at $4^{\circ} \mathrm{C}$ (Christopherson et al., 2005). Cryostat brain sections, $6 \mu \mathrm{m}$, were permeabilized in $0.2 \%$ Triton X-100 for $15 \mathrm{~min}$ and blocked in $10 \%$ FBS plus $1 \%$ BSA for $1 \mathrm{~h}$. Neurons and brain sections were immunostained with primary antibodies overnight at $4^{\circ} \mathrm{C}$ and sec- ondary antibodies for $45 \mathrm{~min}$ at room temperature. Specificity of staining was confirmed by application of secondary antibody in the absence of corresponding primary antibody.

For live-cell antibody feeding (Ehlers, 2000), coverslips were moved to $4^{\circ} \mathrm{C}$ and incubated for $1 \mathrm{~h}$ in $\alpha$ GluR2 (1:150) or $\alpha$ FLAG in Neurobasal media with $5 \%$ BSA. Coverslips were then washed two times for $10 \mathrm{~min}$ each in ice-cold PBS and returned to the incubator in conditioned media. After appropriate ephrinB2 or control treatment, neurons were fixed in $4 \% \mathrm{PFA} / 2 \%$ sucrose and washed in PBS, and secondary antibodies were applied at room temperature for $2 \mathrm{~h}(\alpha \mathrm{GluR} 2)$ or $45 \mathrm{~min}(\alpha$ FLAG). Membrane integrity in AMPAR surface experiments was confirmed by subsequent permeabilization with $0.2 \%$ Triton X-100 for $15 \mathrm{~min}$ and staining of unlabeled internalized GluR2 with a different color secondary antibody.

\section{cDNA and short interfering RNA constructs}

A FLAG-tagged EphB2 construct lacking its ephrin binding domain (fEphB2 $\Delta \mathrm{eb}$ ) was made by removal of the globular domain of fEphB2. EphB2-yellow fluorescent protein (YFP) was generated by inserting the coding sequence for YFP 5' to the EphB2 PDZ (PSD-95/Discs large/zona occludens-1) binding domain at the Apa site. fEphB2, fEphB2_KD, $\mathrm{fEphB} 2 \Delta \mathrm{PDZ}$, fEphB2 $\Delta$ intra (referred to as fEphB2DI in previous work), and fEphA4 were described previously (Dalva et al., 2000; Takasu et al., 2002). PSD-95-GFP, tdTomato, and myc-glutamate receptorinteracting protein 1 (GRIP1) were generous gifts from Dr. David Bredt (University of California, San Francisco, San Francisco, CA), Dr. Roger Tsien (University of California, San Diego, La Jolla, CA), and Dr. Richard Huganir (Johns Hopkins University, Baltimore, MD), respectively. Design of short interfering RNA (siRNA) constructs was accomplished using the Tuschl Rule set (Integrated DNA Technologies, Coralville, IA), and EphB2 siRNA sequences were subcloned into pSuper (Clontech, Cambridge, UK) (Brummelkamp et al., 2002).

\section{Transfection of neuronal and slice culture}

E17-E18 plus $4 \mathrm{~d}$ in vitro (DIV) rat cortical neurons and HEK293T cells were transfected using the calcium phosphate precipitation method (Xia et al., 1996). For siRNA transfections, E17-E18 cortical neurons were transfected in suspension using Lipofectamine 2000 (Takasu et al., 2002) and processed for imaging or recorded from at 9-11 DIV. Transfection of cortical slices was performed using Helios Gene Gun (Bio-Rad, Hercules, CA) (Lo et al., 1994; McAllister, 2004). DNA constructs expressing PSD-95-GFP and tdTomato with and without fEphB2 were coated to $6.25 \mathrm{mg}$ of $1.6 \mu \mathrm{m}$ gold particles in a solution with $0.01 \mathrm{mg} / \mathrm{ml} \mathrm{PVP}, 0.05$ M spermidine, $1 \mathrm{M} \mathrm{CaCl}_{2}$, and $\mathrm{H}_{2} 0$, which was drawn into tubing and coated to the sides. Tubing was cut into cartridges and loaded into the Gene Gun, and gold particles were shot with high-pressure helium (120$140 \mathrm{psi}$ ) into cultured slices in inserts sitting on warmed agarose slabs. Successful delivery of gold particles was visualized with a dissection microscope, and transfection was verified with fluorescence microscopy.

\section{Imaging and analysis}

Cortical neuronal cultures and brain sections were imaged using confocal scanning microscopy (Leica, Nussloch, Germany). Images were $z$-projections of $\sim 3-10$ images taken at $0.5-1 \mu \mathrm{m}$ step intervals (neuronal cultures) or two images taken at $0.5 \mu \mathrm{m}$ step intervals (brain sections). For each experiment, images were taken with identical microscope settings across conditions. For brain slice, cultured slices were removed from the culture dish, placed into artificial CSF (ACSF), and imaged on a two-photon laser confocal scanning microscope [Leica confocal microscope with Tsunami titanium:sapphire mode-locked laser tuned to $890-950 \mathrm{~nm}$, pumped by a $10 \mathrm{~W}$ solid-state laser source (Spectra Physics, Fremont, CA)]. Images were acquired at $1.7 \times$ zoom in stacks with $1.0 \mu \mathrm{m}$ step intervals. All images were acquired blind to experimental condition and analyzed blind to condition in NIH ImageJ. Significance between experimental conditions was determined by ANOVA for all experiments except Figures 2, 4, 5, $c$ and $d$, and $6 g$ (Student's $t$ test). Statistical measures were conducted on a per cell basis, collected from a minimum of three independent experiments.

Puncta analysis. For cocluster analysis in dissociated neurons or brain section, each channel was thresholded with the same value across exper- 
imental conditions and converted to a binary image. Puncta were then defined as continuous pixel clusters of $0.5-7.5 \mu \mathrm{m}$ (except $0.5-11 \mu \mathrm{m}$ for SV2) and coclustering as $>1$ pixel of overlap between two channels. This process was automated by original NIH ImageJ programming. Apparent brightness differences in brain section immunostaining reflect a loss of yellow colocalized puncta (see Fig. $6 a, b$ ), because individual puncta brightness was similar between wild type (WT) and mutants.

For transfection colocalization experiments (see Fig. 1), FLAGpositive and FLAG/GluR2,3 puncta density were determined by thresholding the puncta along $\sim 30-60 \mu \mathrm{m}$ of dendrite beginning $10 \mu \mathrm{m}$ from the soma to best reflect the clusters seen by eye in each cell, blind to transfection condition; the puncta counted were restricted by size as described above. Surface GluR2 images (see Fig. 2) were assessed for total fluorescence per field, and thresholded and assessed for puncta number as described above.

Spine density. Dendritic spine density (see Figs. 1, 5) was determined by manually counting the number of mature spines (mushroom-shaped head, tapered neck) along $50 \mu \mathrm{m}$ of GFP-labeled dendrite for each cell blind to condition.

Heterologous cell coculture. Density (area per pixel) of SV2 puncta $(0.5-11 \mu \mathrm{m})$ was calculated for a field and multiplied by the area of the cocultured HEK293T cell in that field, yielding the "expected" SV2 puncta area for that HEK293T cell. "Observed" SV2 area on that HEK293T cell was measured by thresholding the cell, converting it to a binary image, and subtracting all SV2 labeling in the field not within the borders of the HEK293T cell. The remaining area of SV2 puncta was measured, and percentage difference between observed and expected SV2 area was calculated. Tau-positive staining on HEK293T cells was determined by the same method.

Presynaptic terminal labeling with FM4-64. Presynaptic terminals were loaded by exposing cocultures to $15 \mu \mathrm{M}$ FM4-64 [N-(3-triethylammoniumpropyl)-4-(6-(4-diethylamino)phenyl)hexatrienyl)pyridinium dibromide] (Invitrogen) in depolarizing ACSF (in mм: $90 \mathrm{NaCl}, 55 \mathrm{KCl}, 1$ $\mathrm{MgCl}_{2}, 2 \mathrm{CaCl}_{2}, 20$ glucose, and 10 HEPES, pH 7.2) for $5 \mathrm{~min}$. Cultures were washed five times in ACSF (in mM: $140 \mathrm{NaCl}, 5 \mathrm{KCl}, 1 \mathrm{MgCl}_{2}, 2$ $\mathrm{CaCl}_{2}, 20$ glucose, and 10 HEPES, pH 7.2) to remove non-internalized dye and then imaged by confocal microscopy. Presynaptic terminals were then unloaded by reexposing cultures to depolarizing ACSF for $5 \mathrm{~min}$ and reimaged. $z$-stacks of the loaded and unloaded FM4-64 images were aligned and digitally subtracted in NIH ImageJ. Subtracted images were identically thresholded and converted to a two-bit image, and puncta corresponding to $0.5-20 \mu \mathrm{m}$ were selected to identify presynaptic release sites undergoing activity-dependent dye loss. Observed and expected FM4-64/HEK293T colocalization was determined as described for SV2 puncta. Imaging and analysis were done blind to experimental condition.

siRNA. To calculate SV2 puncta per unit area, the area of the cell after removal of the cell body was determined using thresholded GFP signal, and SV2 puncta $(0.5-11 \mu \mathrm{m})$ contacting the GFP cell were counted.

PSD-95-GFP in brain slice. In brain slice culture experiments, area of a neuron was measured by thresholding tdTomato labeling in each cell to reveal complete morphology, converting to a binary image, and manually deleting unconnected large groups of pixels. Linear density of PSD95-GFP (puncta per micrometer) was calculated by counting the number of PSD-95-GFP puncta on $80 \mu \mathrm{m}$ of dendrite ( $40 \mu \mathrm{m}$ distal apical and $40 \mu \mathrm{m}$ basal for each cell). A puncta was scored as being in a dendritic protrusion if more than approximately three-quarters of the PSD-95GFP puncta was not contacting the shaft or was visible in a tdTomatofilled protrusion; otherwise, a puncta was scored as "shaft."

\section{Electrophysiology}

Whole-cell recordings were made from rat cortical neurons transfected in suspension with GFP and pSuper vector control, siRNA_EphB2.1, or siRNA_EphB2.2. At 9-11 DIV, coverslips were moved into a recording chamber and bathed in a HEPES-buffered ACSF solution (in mM: 140 $\mathrm{NaCl}, 5 \mathrm{KCl}, 1 \mathrm{MgCl}_{2}, 2 \mathrm{CaCl}_{2}, 20$ glucose, and 10 HEPES, pH 7.2). GFP-positive pyramidal neurons were chosen for recording. The internal solution contained the following (in mM): $125 \mathrm{CsGlu}, 5 \mathrm{EGTA}, 2 \mathrm{MgCl}_{2}$, $1 \mathrm{CsCl}_{2}, 2 \mathrm{~K} 2$-ATP, 10 HEPES, and $0.42 \mathrm{Na}-\mathrm{GTP}, \mathrm{pH}$ 7.2. Pipettes were pulled to a 6-9 $\mathrm{M} \Omega$ resistance, and recordings were made for 2-5 min at - $65 \mathrm{mV}$. Tetrodotoxin (TTX) (Sigma), bicuculline (Sigma), and picrotoxin (Sigma) were used at 1, 10, and $10 \mu \mathrm{M}$, respectively. CNQX (Tocris Cookson, Ballwin, MO) and MK-801 [(+)-5-methyl-10,11-dihydro$5 H$-dibenzo [a,d] cyclohepten-5,10-imine maleate] (Sigma) were used at 10 and $50 \mu \mathrm{M}$, respectively. All data were collected at $5 \mathrm{kHz}$ and filtered at $1 \mathrm{kHz}$; events were detected in Clampfit 9.2 (Molecular Devices, Palo Alto, CA).

\section{Results}

\section{EphB2 colocalizes with AMPARs in cortical neurons}

To begin to understand the role of EphB2 in organizing the components of a mature postsynaptic terminal, we studied cortical neurons at 7 DIV because, at this time, cultured neurons begin a robust phase of synaptogenesis but have few mature dendritic spines or synaptic specializations (Papa et al., 1995; O'Brien et al., 1997; Dalva et al., 2000). Given the observation that loss of EphB1-EphB3 disrupts both NMDAR and AMPAR clustering in neuronal culture (Henkemeyer et al., 2003), we examined whether overexpressed EphB2 might associate not only with NMDARs but also AMPARs after clustering of EphB. Cultured cortical neurons at 4 DIV were transfected with FLAG epitopetagged wild-type EphB2 (fEphB2) and GFP. At 7 DIV, neurons were treated with activated ephrinB2 for $16 \mathrm{~h}$ to induce clustering of fEphB2. Exogenously expressed EphB2 was detected using anti-FLAG antibodies, and neurons were immunostained with antibodies against either GluR2,3 or NR2B. As expected from previous work (Dalva et al., 2000), NR2B labeling colocalized with fEphB2 after ephrinB2 treatment (Fig. 1a). However, we also found that $>70 \%$ of fEphB2 puncta colocalized with clusters of the endogenous AMPAR subunit GluR2,3 along dendrites (Fig. $1 c-e)$. Thus, after ephrinB2 treatment, clusters of EphB2 colocalize with both NMDA- and AMPA-type glutamate receptors in cortical neurons. These results were confirmed with immunostaining of endogenous EphB and glutamate receptors (data not shown).

We next wanted to investigate how AMPARs might become clustered with EphB2. Calcium influx through NMDAR is thought to have a critical role in the trafficking of AMPARs at and around synapses (Ehlers, 2000; Bredt and Nicoll, 2003). EphB2 kinase activity induces Src-dependent phosphorylation of NMDAR subunits, causing enhanced NMDAR-mediated $\mathrm{Ca}^{2+}$ flux in response to glutamate (Takasu et al., 2002). Thus, the increased colocalization of EphB2 and AMPAR subunits after ephrinB2 treatment might reflect an EphB-mediated potentiation of NMDAR-dependent $\mathrm{Ca}^{2+}$ flux and subsequent recruitment of AMPARs. To test this hypothesis, we overexpressed a FLAG epitope-tagged kinase-dead EphB2 (fEphB2_KD) in cortical neurons, which is unable to enhance NMDAR-mediated $\mathrm{Ca}^{2+}$ flux, and assessed colocalization of anti-FLAG staining with endogenous GluR2,3. Mutation of the EphB2 kinase domain did not impact the ability of this exogenous EphB2 to cocluster with AMPAR subunits GluR2,3 after treatment with activated ephrinB2 (Fig. $1 c, h, i$ ). In addition, we found that, in the presence of the NMDAR antagonist APV, EphB-AMPAR coclusters still form after ephrinB2 treatment (data not shown). These data suggest that the colocalization of EphB and AMPARs might rely on protein-protein interactions involving the two receptors and is not dependent on an EphB kinase-dependent potentiation of NMDAR activity. 

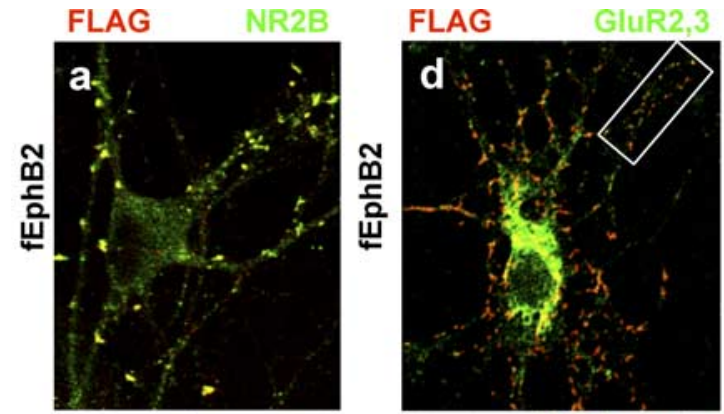

\section{FLAG}
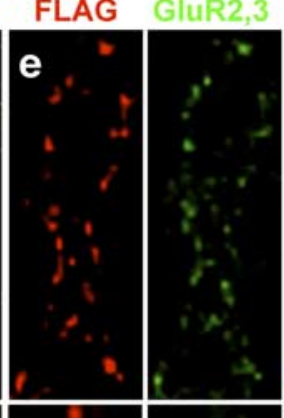

Merge
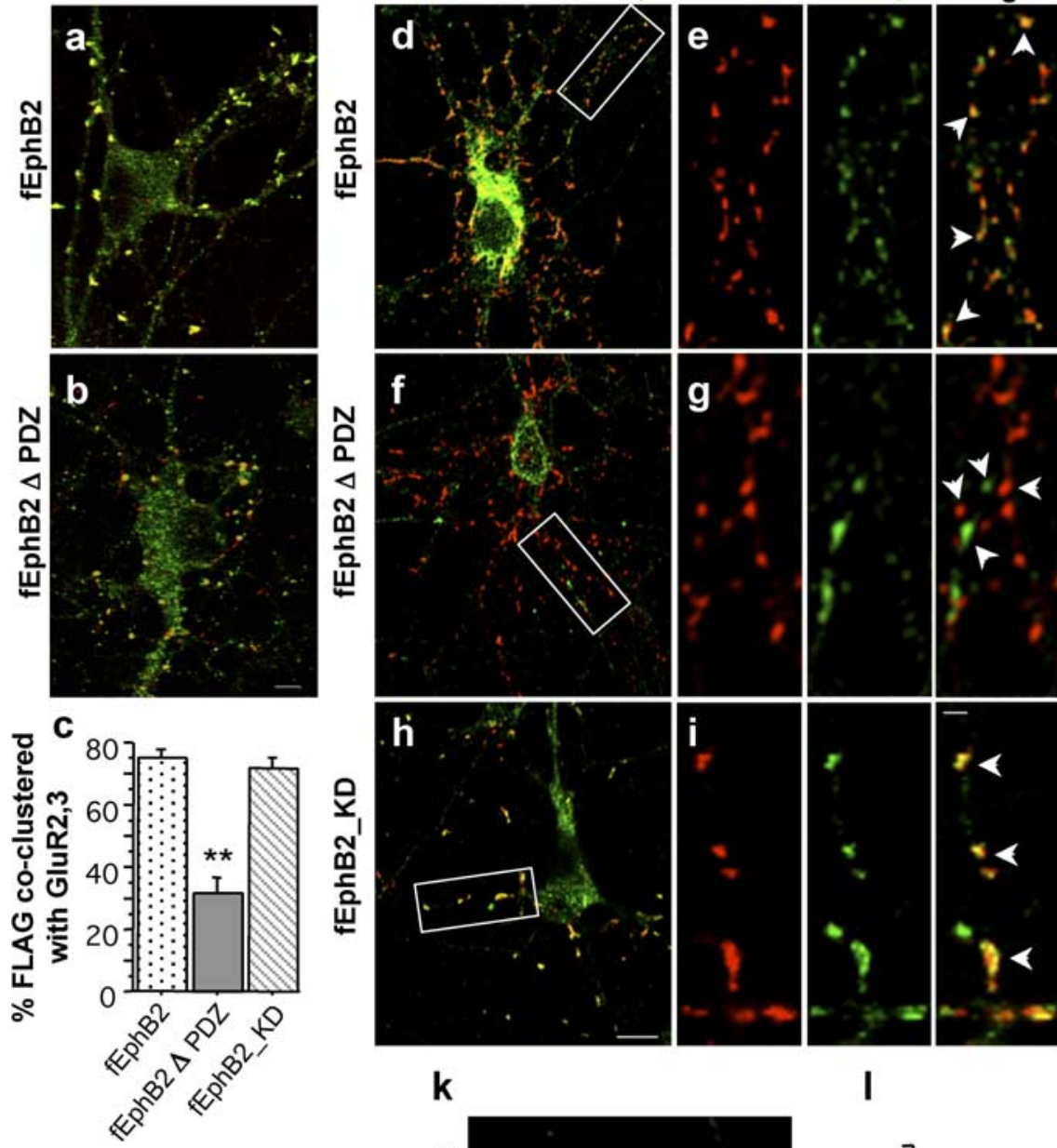

\section{k}

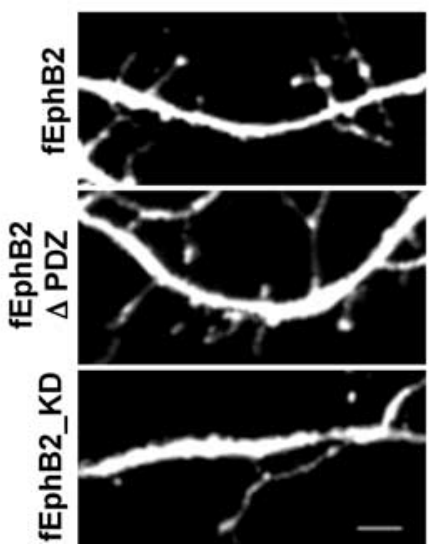

1

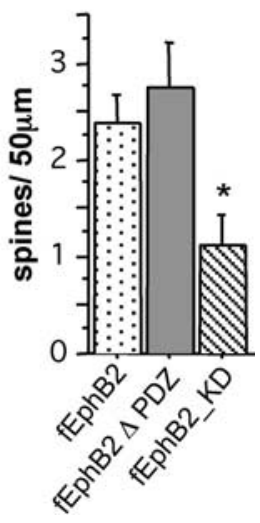

Figure 1. The PDZ binding domain of EphB2 is required for EphB colocalization with AMPA receptors but not NMDA receptors. $\boldsymbol{a}$, Representative image of 7 DIV rat cortical neuron transfected with fEphB2 at 4 DIV and immunostained for FLAG epitope (red) and NR2B (green). Yellow indicates colocalization. $\boldsymbol{b}$, Representative image of 7 DIV rat cortical neuron transfected with fEphB2 $\triangle$ PDZ at 4DIV and immunostained for FLAG (red) and NR2B (green). Yellow indicates colocalization. Scale bar, $5 \mu \mathrm{m}$. $c$, Quantification of percentage of FLAG-positive puncta colocalized with GluR2,3 puncta in dendrites of neurons transfected with fEphB2 $(n=35)$, fEphB2 $\triangle \mathrm{PDZ}(n=30)$, or fEphB2_KD $(n=45)$. $\boldsymbol{d}$, Representative image of 7 DIV rat cortical neuron transfected with fEphB2 at 4 DIV and immunostained for FLAG (red) and GluR2,3 (green). Yellow indicates colocalization. $\boldsymbol{e}$, Highmagnification view of boxed region of dendrite from fEphB2-transfected cell. Arrows and yellow puncta indicate colocalization. $f$ Representative image of 7 DIV rat cortical neuron transfected with fEphB2 $\triangle$ PDZ at 4 DIV and immunostained for FLAG (red) and GluR2,3 (green). $\boldsymbol{g}$, High-magnification view of boxed region of dendrite from fEphB2 $\triangle$ PDZ-transfected cell. Arrows indicate adjacent but non-overlapping puncta of GluR2,3 (green) and fEphB2 $\triangle$ PDZ (red). $\boldsymbol{h}$, Representative image of 7 DIV rat cortical neuron transfected with fEphB2_KD at 4 DIV and immunostained for FLAG (red) and GluR2,3 (green). In merged image, yellow indicates colocalization. Scale bar, $20 \mu \mathrm{m}$. $\boldsymbol{i}$, High-magnification view of boxed region of dendrite from fEphB2_KD-transfected cell. Arrows and yellow puncta indicate colocalization. Scale bar, $2 \mu \mathrm{m}$. $\boldsymbol{j}$, Quantification of GluR2,3 puncta density in dendrites of neurons transfected with GFP alone $(n=12)$ or GFP plus fEphB2, fEphB2 $\triangle \mathrm{PDZ}$, or fEphB2_KD. $\boldsymbol{k}$, Representative dendrites from 7 DIV rat cortical neurons cotransfected at 4 DIV with GFP and fEphB2, fEphB2 $\triangle$ PDZ, or fEphB2_KD. Scale bar, $2 \mu \mathrm{m}$. $I$, Quantification of dendritic spine density in 7 DIV neurons transfected with fEphB2 $(n=18)$, fEphB2 $\triangle$ PDZ ( $n=16)$, or fEphB2_KD ( $n=$ 27). Error bars indicate SEM. ${ }^{*} p<0.005 ;{ }^{* *} p<0.0001$.

\section{PDZ binding domain interactions} mediate EphB2 colocalization with AMPARs

One attractive candidate domain on EphB2 for regulating the EphB-AMPAR association is the PDZ binding domain, which mediates an interaction between EphB2 and the AMPAR binding proteins PKC-interacting protein 1 (PICK1) or GRIP1 (Torres et al., 1998). EphB and GluR2,3 fail to coimmunoprecipitate when overexpressed in HEK293T cells, suggesting that the EphB-AMPAR interaction requires additional proteins not expressed in HEK293T cells (Dalva et al., 2000). However, GST-fusion proteins consisting of the PDZ binding domain of EphB2 can pull down AMPAR subunits from neuronal lysates (Contractor et al., 2002). We asked whether the PDZ binding domain of EphB2 is necessary for the colocalization of EphB2 and GluR2,3 in neurons.

Cultured cortical neurons at 4 DIV were transfected with a FLAG-tagged EphB2 in which the PDZ binding domain was deleted (fEphB2 $\Delta \mathrm{PDZ}$ ) along with GFP and immunostained with antibodies against FLAG and either GluR2,3 or NR2B. As predicted from previous work showing that the EphB-NMDAR interaction requires only the extracellular domains of these proteins (Dalva et al., 2000), NR2B labeling colocalized with fEphB2 $\Delta$ PDZ after ephrinB2 treatment (Fig. 1b). Strikingly, only $\sim 30 \%$ of fEphB2 $\Delta$ PDZ puncta along dendrites colocalized with GluR2,3 (Fig. $1 c, f, g$ ). The reduction of AMPAR-EphB2 colocalization is not likely to reflect failed trafficking of fEphB2 $\Delta$ PDZ compared with the other FLAG-tagged EphB2 constructs, because live-cell anti-FLAG labeling indicates that fEphB2, fEphB2 $\Delta$ PDZ, and fEphB2_KD expressed in cortical neurons are clustered and able to reach the cell surface after ephrinB2 treatment (data not shown); we did not observe a significant difference in the density of fEphB2, fEphB2 $\Delta \mathrm{PDZ}$, or fEphB2_KD puncta when overexpressed in neurons (fEphB2, $0.28 \pm 0.02$ puncta/ $\mu \mathrm{m}$; fEphB2 $\Delta \mathrm{PDZ}, 0.24 \pm 0.02$ puncta/ $\mu \mathrm{m}$; fEphB2_KD, $0.27 \pm 0.02$ puncta $/ \mu \mathrm{m}$; $p>0.25)$. Although there is reduced colocalization of fEphB2 $\triangle \mathrm{PDZ}$ and AMPAR subunits, both proteins appear clustered and are often adjacent although not overlapping (Fig. 1g, arrows). This observation, together with the fact that $\mathrm{fEphB} 2 \Delta \mathrm{PDZ}$ colocalizes with NR2B, suggests that $\mathrm{fEphB} 2 \Delta \mathrm{PDZ}$ is competent to reach putative synaptic sites and associate with glutamate receptors. Thus, the PDZ binding domain of EphB2 is involved in the clustering of EphB2 
with AMPARs in a complex with AMPAR-binding proteins but is not required for EphB2 to associate with NMDARs.

EphB2 overexpression increases dendritic AMPAR density via a PDZ binding domain-dependent mechanism

Although EphB2 and AMPARs colocalize in dendrites, we wanted to investigate whether this association causes the formation of more AMPAR clusters. We measured the density of GluR2,3 puncta in 7 DIV cortical neurons expressing either GFP alone or fEphB2 plus GFP after treatment with ephrinB2 for $16 \mathrm{~h}$. Expression of fEphB2 resulted in a 26\% increase in GluR,3 puncta compared with GFP alone (Fig. 1j). To test whether this effect requires the EphB2 PDZ binding domain, we examined neurons expressing fEphB2 $\triangle \mathrm{PDZ}$, a construct that is still kinase active. In these cells, the overall density of GluR2,3 clusters did not differ from GFP controls (Fig. 1j), indicating that the EphB2 PDZ binding domain is required not only for EphB2 and AMPARs to associate but also for the EphB2-mediated increase in AMPAR puncta. Interestingly, overexpression of fEphB2_KD also had no effect on overall GluR2,3 density (Fig. 1j), despite the finding that density of fEphB2_KD/GluR2,3 coclusters appears similar to WT fEphB2/GluR2,3 coclusters (WT fEphB2, $0.21 \pm 0.02$ puncta/ $\mu \mathrm{m}$; fEphB2_KD, $0.19 \pm 0.01$ puncta/ $\mu \mathrm{m}$ ). To understand this effect further, we examined the density of those AMPAR clusters not colocalized with FLAG staining in fEphB2- or fEphB2_KDexpressing neurons. With overexpression of fEphB2_KD, we observed a $30 \%$ reduction in the density of non-FLAG localized GluR2,3 clusters compared with WT fEphB2 (WT fEphB2, $0.13 \pm 0.02 \mathrm{puncta} / \mu \mathrm{m} ; \mathrm{fEphB2} \_\mathrm{KD}, 0.09 \pm 0.01 \mathrm{puncta} / \mu \mathrm{m}$; $p<0.05)$. Thus, although the PDZ binding domain of fEphB2_KD still functions to cluster AMPARs by protein-protein interactions, this local effect is offset by a cell-wide loss of AMPAR clusters not associated with exogenously expressed kinase-inactive EphB2.

\section{Disruption of EphB2-AMPAR colocalization after deletion of EphB2 PDZ binding domain is not attributable to loss of dendritic spines}

The absence of EphB1-EphB3 from cultured hippocampal neurons results in the loss of both spines and glutamate receptor clusters (Henkemeyer et al., 2003). One possible explanation for both this result and our finding that EphB2-AMPAR colocalization is disrupted with deletion of the EphB2 PDZ binding domain is that loss of AMPAR coclustering occurs as a direct consequence of changes in dendritic spine morphology. We therefore assessed the density of spines in our 7 DIV cortical neurons coexpressing GFP and fEphB2, which has been shown to increase spine density (Penzes et al., 2003), fEphB2 2 PDZ, or fEphB2_KD after ephrinB2 treatment. Although the density of mature mushroomshaped spines is relatively low at this age in culture (Papa et al., 1995; Ethell et al., 2001), we found a decrease in spine density with overexpression of fEphB2_KD compared with fEphB2 (Fig. $1 k, l)$, consistent with previous work (Ethell et al., 2001). Dendritic spine density in neurons expressing fEphB2 $\triangle \mathrm{PDZ}$, however, did not appear different from those expressing fEphB2 (Fig. $1 k, l)$. Thus, overexpression of fEphB2 $\Delta \mathrm{PDZ}$ in young neurons results in reduction of EphB2-AMPAR coclustering without affecting spine density, whereas overexpression of fEphB2_KD causes a reduction in spine density without affecting the ability of EphB2 and AMPARs to colocalize. Mutation of either of these domains blocks the EphB2-induced enhancement of AMPAR clusters in dendrites: $\mathrm{fEphB} 2 \Delta \mathrm{PDZ}$ does so via loss of local interactions between the two proteins, and fEphB2_KD through a global effect on AMPARs not localized to sites of EphB2 clusters. These data indicate that distinct signaling domains of EphB2 can control its ability to cluster postsynaptic proteins and shape spine morphology through different mechanisms and suggest that certain aspects of EphB-dependent synaptogenesis are dissociable.

\section{EphrinB2 treatment maintains the surface localization of AMPARs}

To begin to examine whether the EphB-AMPAR interaction is functionally relevant to synaptic maturation, we investigated whether ephrinB treatment affects the surface expression of AMPAR clusters. PDZ binding domain interactions can regulate AMPAR trafficking (Song and Huganir, 2002), and recent evidence suggests that EphB2 signaling can regulate the recycling of membrane proteins (Irie et al., 2005). Together with our data demonstrating that EphB-AMPAR coclustering occurs via PDZ binding domain interactions, these results suggest that ephrinB treatment of cultured neurons might alter the membrane recycling of AMPARs. To address whether changes in surface localization of AMPARs are induced after ephrinB application, we labeled surface-expressed receptors using live-cell antibody labeling at $4^{\circ} \mathrm{C}$ with an antibody recognizing the extracellular domain of GluR2. After labeling of surface GluR2, neurons were incubated at $37^{\circ} \mathrm{C}$ to allow receptor recycling and trafficking and were treated with either activated ephrinB2 or control reagents for 1 or $16 \mathrm{~h}$. We quantified surface fluorescence and number of clusters of GluR2 after labeling with a fluorescent secondary antibody on fixed neurons in nonpermeabilizing conditions. After treatment with control, few labeled clusters of surface GluR2 remained after either 1 or $16 \mathrm{~h}$ (Fig. 2a,c). However, with ephrinB treatment, at both 1 and $16 \mathrm{~h}$ time points, there was more surface-expressed GluR2 per field compared with control conditions (Fig. 2b,d,e). This effect does not require NMDAR activity, because enhanced AMPAR surface staining after ephrinB2 application was not blocked by the presence of APV (total fluorescence normalized to control $1 \mathrm{~h}$, control $1 \mathrm{~h}, 1.0 \pm 0.04$; control plus APV $1 \mathrm{~h}, 1.01 \pm 0.03$; ephrinB2 $1 \mathrm{~h}, 1.34 \pm 0.04$; ephrinB2 plus APV $1 \mathrm{~h}, 1.31 \pm 0.05$; control $16 \mathrm{~h}$, $1.04 \pm 0.06$; control plus APV 16 h, $0.98 \pm 0.04$; ephrinB2 $16 \mathrm{~h}$, $1.24 \pm 0.05$; ephrinB2 plus APV 16 h, $1.29 \pm 0.04 ; p<0.01$ for all ephrinB2 compared with control conditions).

We next investigated whether the observed increase in AMPAR surface localization with ephrinB2 treatment requires the PDZ binding domain of the EphB2 receptor. We transfected 4 DIV cortical neurons with GFP alone or GFP plus WT fEphB2, fEphB2 $\triangle \mathrm{PDZ}$, or fEphB2_KD. At 7 DIV, these neurons were treated for $16 \mathrm{~h}$ with ephrinB2 or control, fixed under nonpermeabilizing conditions, and immunostained with the anti-GluR2 antibody. As expected, ephrinB application to neurons expressing GFP caused an increase in surface GluR2 puncta density (Fig. $2 f)$. Neurons expressing fEphB2 plus GFP had a significantly larger increase in surface GluR2 puncta density after ephrinB treatment relative to those neurons expressing only GFP (Fig. 2f), indicating that the presence of more EphB2 in the postsynaptic cell enhances ephrinB-dependent surface retention of AMPARs. Analysis of neurons expressing fEphB2 $\triangle \mathrm{PDZ}$ plus GFP revealed that removal of the EphB2 PDZ binding domain blocks the expected increase in surface GluR2 clusters after ephrinB2 treatment (Fig. 2f). Thus, the PDZ binding domain of EphB2 is required for the ephrinB-mediated stabilization of AMPARs on the cell surface. Consistent with previous work (Irie et al., 2005), expression of fEphB2_KD resulted in a modest increase in surface-localized GluR2 at rest without ephrinB treatment $(1.39 \pm 0.13$-fold increase when normalized to GFP control 

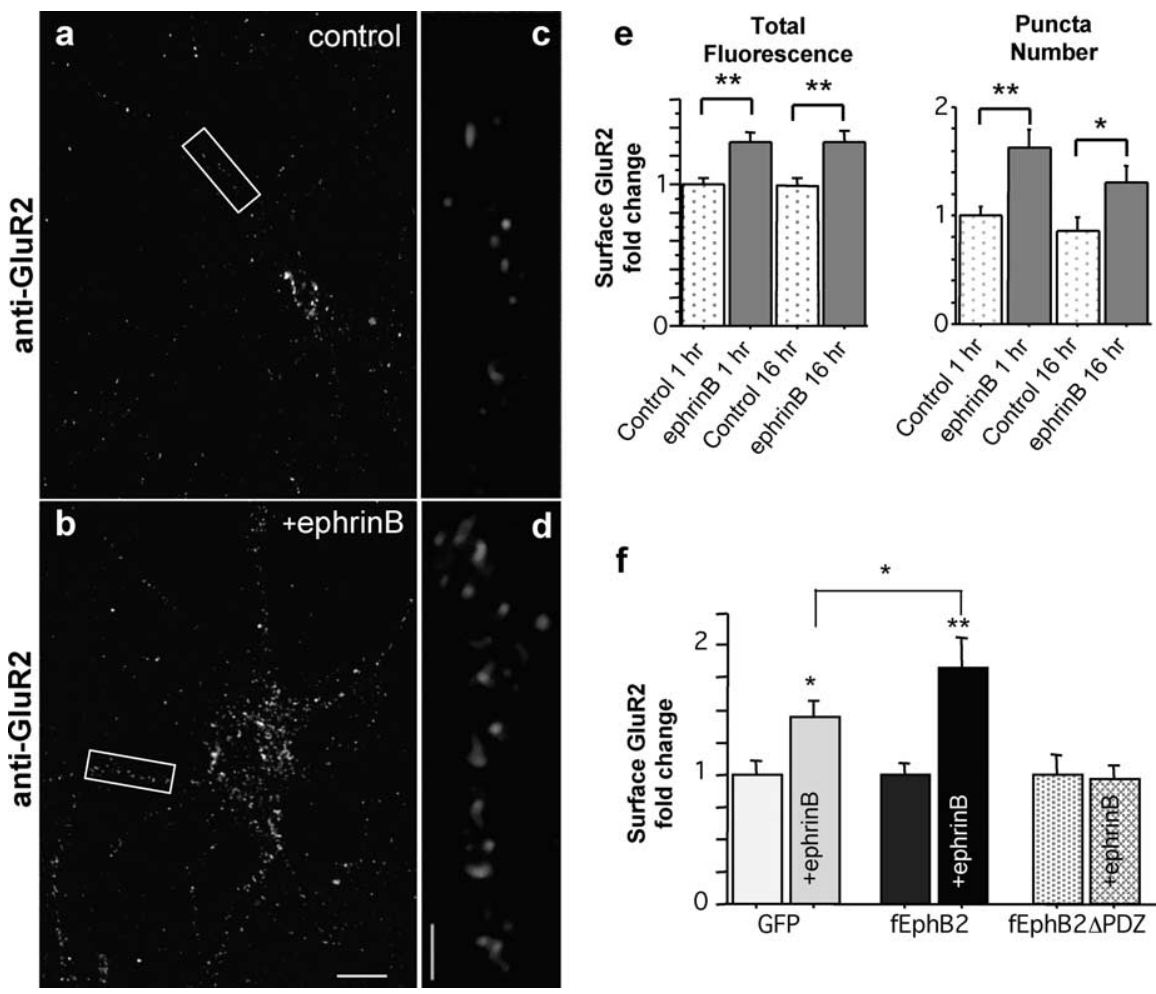

Figure 2. Treatment of cortical neurons with ephrinB2 results in enhanced surface retention of AMPA receptors. $\boldsymbol{a}, \boldsymbol{b}$, Representative image of 7 DIV rat cortical neuron immunostained with live-cell labeling of surface GluR2 at $4^{\circ} \mathrm{C}$ followed by treatment with control (a) or ephrinB2 (b) for $1 \mathrm{~h}$ at $37^{\circ} \mathrm{C}$. Scale bar, $10 \mu \mathrm{m}$. $\boldsymbol{c}, \boldsymbol{d}$, High-magnification views of boxed region of dendrite from control-treated ( $\boldsymbol{a}$ ) or ephrinB2-treated $(\boldsymbol{b})$ neurons. Scale bar, $2 \mu \mathrm{m} . \boldsymbol{e}$, Quantification of fold change in surface GluR2 fluorescence and cluster number per field after treatment with control for 1 or $16 \mathrm{~h}(n=28, n=22)$ or ephrinB2 for 1 or $16 \mathrm{~h}$ ( $n=27$, $n=25)$. $f$, Quantification of fold change in GluR2 puncta density on dendrites of neurons transfected with GFP alone or GFP plus either fEphB2 or fEphB2 $\triangle \mathrm{PDZ}$ and treated with control or ephrinB2 for $16 \mathrm{~h}$ (GFP: control, $n=6$ cells; ephrinB, $n=15$; fEphB2: control, $n=10$; ephrinB, $n=10$; fEphB2 $\triangle \mathrm{PDZ}$ : control, $n=6$; ephrinB, $n=8$; values are normalized to the control treatment for a given transfection condition). Error bars indicate SEM. ${ }^{*} p<0.05 ;{ }^{* *} p<0.005$.

treatment). Treatment of fEphB2_KD-expressing neurons with ephrinB2 did not induce any additional changes in surface GluR2 labeling (0.93 \pm 0.14 -fold change when normalized to fEphB2_KD control treatment; $1.29 \pm 0.19$-fold increase when normalized to GFP control treatment). These findings indicate that activation of EphB with ephrinB enhances the retention of AMPAR clusters on the cell surface or in the recyclable pool at a synapse. This activity requires both the EphB2 PDZ binding domain for local AMPAR interactions and EphB2 kinase signaling for more global control of AMPAR trafficking. Together with previous work (Dalva et al., 2000; Ethell et al., 2001; Penzes et al., 2003), our experiments suggest that EphB2 can regulate the localization of NMDARs, AMPARs, and the formation of dendritic spines through distinct domains.

\section{EphB2 expressed in non-neuronal cells induces differentiation of contacting axons}

Functional synapses must contain presynaptic vesicles apposed to postsynaptic receptors. Although EphB signaling appears to regulate the localization of postsynaptic molecules, it is not known whether EphB directly controls presynaptic differentiation. To test the possibility that a trans-synaptic signal involving postsynaptic EphB is able to organize presynaptic specializations, we used a heterologous cell coculture system (Scheiffele et al., 2000; Graf et al., 2004). In this assay, HEK293T cells were transfected with FLAG-tagged Eph or control constructs, dissociated 24-28 h later, and plated on top of 7 DIV rat cortical neurons.

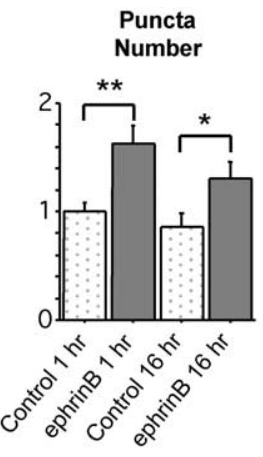

Neurons tolerated coculture with transfected HEK293T cells well, with no apparent effects on cell survival. After 16-18 h, the cocultures were fixed and stained for each exogenous protein expressed in the HEK293T cells as well as endogenous SV2. We used the SV2 staining of neurons to assay the number of presynaptic specializations under different coculture conditions. Anti-FLAG staining of unpermeabilized cells revealed that each expressed FLAG-tagged construct is surface localized without significant differences in fluorescence intensity, and we did not find a correlation between HEK293T cell area and SV2 staining on that cell in any transfection condition $\left(R^{2}<0.05\right)$.

To determine whether exogenously expressed constructs in HEK293T cells induce presynaptic vesicle clustering, we quantified the total area of SV2-positive puncta on axons contacting the HEK293T cells 16-18 h after coculture. Consistent with published work (Krueger et al., 2003), in our 7 DIV cortical cultures, a significant percentage of presynaptic immunostained sites are not colocalized with postsynaptic clusters. Thus, rather than consider the SV2 puncta not associated with postsynaptic markers as exogenously induced, we measured the density of SV2 staining in the field surrounding an HEK293T cell and compared that value with the SV2 staining on the cell itself. The presence of an HEK293T cell with no effect on the endogenous staining pattern should result in the same SV2 staining per pixel as the surrounding field (100\% of expected). In fact, we found using our measure that the area of SV2 puncta on HEK293T cells transfected with GFP did not differ from the expected value $(\sim 100 \%)$ calculated from SV2 density of the surrounding field (Fig. 3a,e).

We next asked whether expression of fEphB2 in HEK293T cells might trigger formation of presynaptic specializations. In cells transfected with fEphB2, we found a $>260 \%$ increase in the area of SV2 puncta on contacting axons (Fig. 3b,e). Interestingly, the SV2 staining pattern often outlined the edges of fEphB2transfected HEK293T cells, in which surface fEphB2 would be most likely to contact axons (Fig. 3b,d). Because EphB2 interactions with the PDZ domain protein GRIP1 have been implicated in the proper presentation of EphB2 to ephrinB (Torres et al., 1998; Contractor et al., 2002; Hoogenraad et al., 2005), we also investigated whether cotransfection of fEphB2 with GRIP1 might enhance the ability of EphB2 to signal trans-synaptically. We found that coexpression with GRIP1 does not result in a significant difference from EphB2 alone (Fig. 3e). Thus, expression of EphB2 alone in non-neuronal cells is able to induce recruitment of synaptic vesicle clusters.

EphB-ephrinB interactions result in bidirectional signaling that can coordinate events between two cells, such as the formation of boundaries in rhombomeres (Xu et al., 1999) and the induction of mossy fiber long-term potentiation (Contractor et al., 2002). The ability of EphB2 expressed in a putative postsyn- 
aptic cell to trigger recruitment of presynaptic vesicles in a contacting axon presumably occurs via binding of ephrin, because there are no other known ligands of EphBs. To test this hypothesis, we first examined whether ephrinBs are localized to axons and synapses in cortical neuronal cultures using specific antibodies raised against ephrinB subtypes. Immunostaining of ephrinB1 and ephrinB3 along with the axonal marker tau in 7 DIV cortical cultures revealed that both of these ephrinB ligands are found in axons, with a high coincidence of ephrinB and tau labeling (Fig. 3f). By staining cortical neurons with antibodies against ephrinBs, the excitatory presynaptic marker VGLUT1, and an excitatory postsynaptic marker (SynGAP or PSD-95), we also found that ephrinB1 and ephrinB3 are enriched in synapses at 8 and 22 DIV neurons (data not shown) (Fig. 3g). These data are consistent with a model in which postsynaptic EphB2 binds axonal ephrinB trans-synaptically to induce recruitment of presynaptic vesicles to interaction sites. To determine whether the EphB-ephrin interaction is required for this effect, we transfected a FLAG-tagged EphB2 construct lacking its ephrin-binding globular domain (fEphB2 $\Delta \mathrm{eb}$ ) into HEK293T cells. Coculture of fEphB2 $\Delta$ ebexpressing cells with neurons for $16-18 \mathrm{~h}$ resulted in no increased SV2 staining (Fig. $3 c-e)$. In addition, $\mathrm{fEphB} 2 \Delta \mathrm{eb}$ expressed in HEK293T cells cocultured with neurons did not induce clustering of ephrinBs (Fig. 3h). In contrast, expression of fEphB2 in HEK293T cells caused robust clustering of ephrinBs in cocultured neurons, frequently with SV2 coclustered at the same sites (Fig. 3h). Together, these findings demonstrate the necessity of the globular domain of the EphB2 protein to recruit ephrinBs and synaptic vesicle clusters.

Another possible explanation for the observed increase in SV2 staining on nonneuronal cells expressing $\mathrm{fEphB} 2$ is that, rather than a direct induction effect, there is greater axon contact area on these cells compared with controls. We immunostained cocultures of neurons and HEK293T cells expressing GFP, fEphB2 or fEphB2 $\Delta$ eb for the axonal marker tau and examined whether any of these conditions resulted in localized increases in axonal density compared with the surrounding field. We found no significant differences in the axonal contact area per cell for each condition (percentage change of taupositive staining, GFP, $124.3 \pm 23.0$; fEphB2, $140.6 \pm 26.8$; fEphB2 $\Delta \mathrm{eb}, 96.3 \pm 7.1 ; p \geq 0.2$ ), indicating that the change in synaptic vesicle cluster density induced by fEphB2-expressing cells cannot be explained by local axonal sprouting.

We next wanted to rule out the possibility that an EphB2 intracellular signal begins a cascade of events within an HEK293T
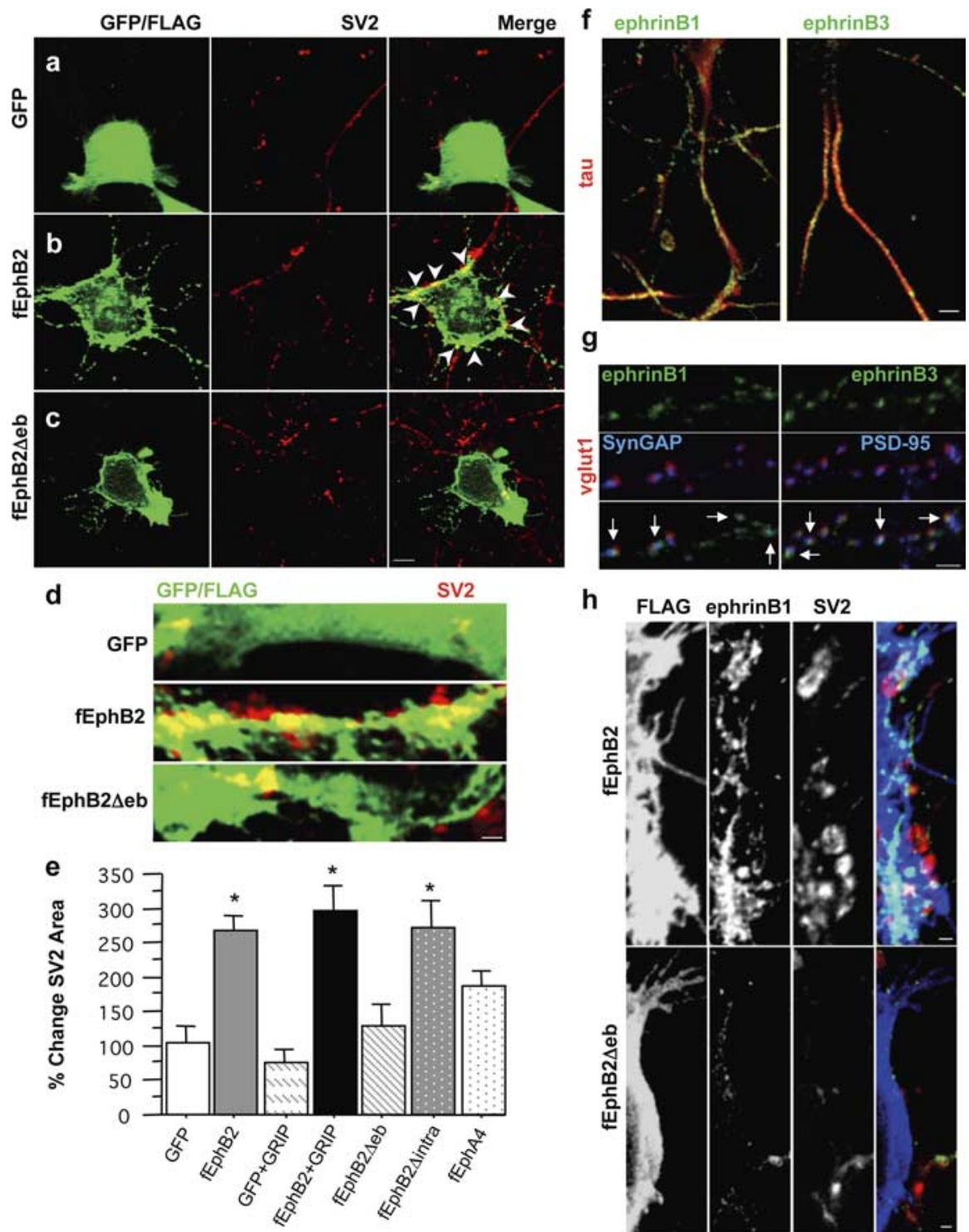

h

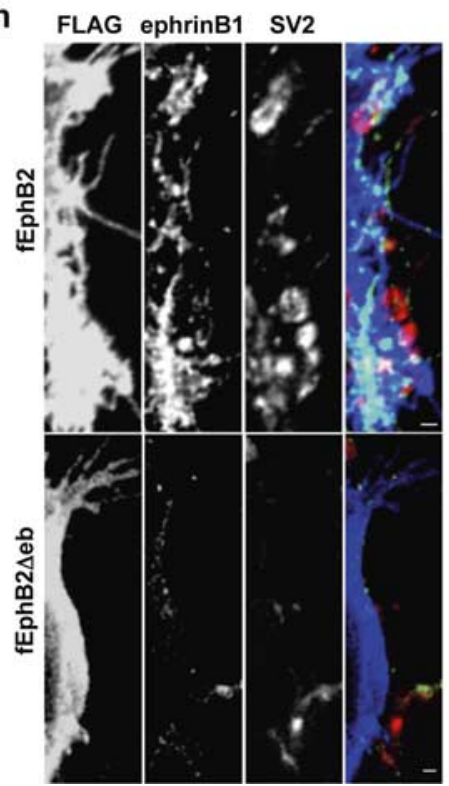

Figure 3. Expression of $\mathrm{fEphB2}$ in non-neuronal cells cocultured with neurons triggers clustering of presynaptic vesicles in contacting axons. $\boldsymbol{a}-\boldsymbol{c}$, Representative image of HEK293T cell transfected with GFP $(n=33)$, fEphB2 ( $n=76)$, or fEphB2 $\Delta$ eb $(n=12)$ and cocultured with 7 DIV rat cortical neurons for $16-18 \mathrm{~h}$. GFP or FLAG (green) and SV2 (red). Arrows indicate SV2 puncta on the border of the fEphB2-expressing HEK293T cell. Scale bar, $4 \mu \mathrm{m}$. $\boldsymbol{d}$, High-magnification view of border of transfected HEK293T cell and GFP/SV2 or FLAG/SV2 overlap (yellow). Scale bar, $1 \mu \mathrm{m}$. $\boldsymbol{e}$, Quantification of percentage difference between the observed and expected area of SV2 puncta on an HEK293T cell transfected with the indicated construct(s) (fEphB2 plus GRIP1, $n=$ 64 ; GRIP1 plus GFP, $n=20 ;$ fEphB2 $\Delta$ intra, $n=27$; fEphA4, $n=54$ cells). $\boldsymbol{f}$, Representative 7 DIV cortical neurons immunostained with antibodies against tau (red) and either ephrinB1 or ephrinB3 (green). Yellow indicates overlap. Scale bar, $2 \mu \mathrm{m} . \boldsymbol{g}$, Representative dendrites from 22 DIV cortical neurons immunostained for ephrinB1 (green), VGLUT1 (red), and SynGAP (blue), or ephrinB3 (green), VGLUT1 (red), and PSD-95 (blue). Arrows indicate colocalization. Scale bar, $2 \mu \mathrm{m}$. $\boldsymbol{h}$, Representative image of border of fEphB2- or fEphB2 $\Delta$ eb-expressing HEK293t cell (blue) and immunostaining of endogenous ephrinB1 (green) and SV2 (red). Scale bars, $1 \mu \mathrm{m}$. Error bars indicate SEM. ${ }^{*} p<0.002$ (comparing indicated construct with GFP control).

cell, leading ultimately to a retrograde cue for synaptic vesicle recruitment. By coculturing HEK293T cells expressing an EphB2 mutant lacking its entire intracellular domain including the juxtamembrane tyrosines (fEphB2 $\Delta$ intra) with 7 DIV neurons, we found that the EphB2 extracellular domain alone is sufficient to trigger clustering of presynaptic vesicles (Fig. 3e). To investigate whether accumulation of synaptic vesicle clusters at HEK293T cell-axon contact points is specific to EphB binding of ephrinB, we took advantage of the promiscuous nature of Eph-ephrin interactions. A member of the EphA family, EphA4, also binds 


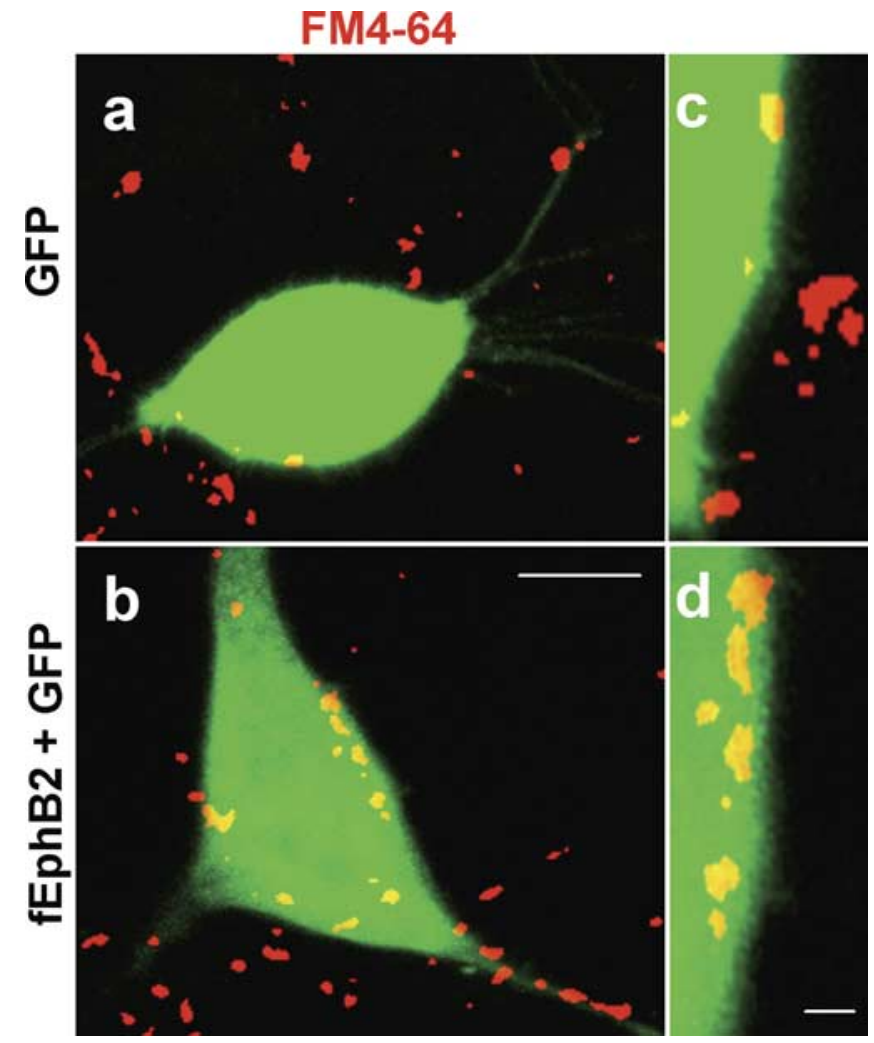

Figure 4. EphB2 induces recruitment of functional presynaptic specializations. $\boldsymbol{a}, \boldsymbol{b}$, Representative image of HEK293T cell transfected with GFP $(n=15)$ or GFP plus fEphB2 $(n=14)$ and cocultured with 7 DIV cortical neurons for 18-24 h. GFP (green) and FM4-64 (red) labeled release sites. Scale bar, $10 \mu \mathrm{m}$. $\boldsymbol{c}, \boldsymbol{d}$, High-magnification view of cell border in $\boldsymbol{a}$ and $\boldsymbol{b}$, respectively. Scale bar, $2 \mu \mathrm{m}$.

ephrinB family members (Flanagan and Vanderhaeghen, 1998). If only the binding of ephrinBs were necessary for presynaptic differentiation of axons onto non-neuronal cells, EphA4 would also induce clustering of SV2. Although ephrinBs still cluster on HEK293T cells expressing FLAG-tagged EphA4 (fEphA4; data not shown), we found that expression of fEphA4 in HEK293T cells cocultured with neurons results in a moderate but not significant increase in SV2 staining compared with GFP control, taking into account the variance of the dataset (Fig. 3e); however, the effect of fEphA4 is significantly less than that of $\mathrm{fEphB} 2$ in our assay $(p<0.03)$.

Finally, we asked whether the recruitment of presynaptic marker proteins to non-neuronal cells expressing fEphB2 represents the formation of functional presynaptic specializations by labeling activity-dependent vesicle recycling with the styryl dye FM4-64. HEK293T cells expressing either fEphB2 plus GFP or GFP alone were cocultured with 7 DIV cortical neurons for 18-24 h. Presynaptic release sites were labeled with FM4-64, and HEK293T cells were identified by GFP fluorescence. We found that cells expressing GFP alone did not induce increased FM4-64 labeling (Fig. 4a) (1.32 \pm 0.13 -fold change compared with surrounding field); however, we measured a $2.6 \pm 0.27$ fold increase in the puncta labeling on cells expressing fEphB2 plus GFP (Fig. 4b) ( $p<0.005)$. Similar to SV2 staining, these puncta were often observed along the cell border (Fig. $4 d$ ) or on small cell protrusions presumed to be EphB-ephrinB contact points. Together, these data argue strongly that EphB2 trans-synaptic signaling can initiate the formation or stabilization of presynaptic specializations.
Knockdown of EphB2 in cortical neurons reduces the number of excitatory synaptic inputs

To investigate whether postsynaptic EphB2 also controls the number of presynaptic contacts onto neurons, we used an siRNA-knockdown approach. This method allowed us to examine how decreased postsynaptic EphB2 expression in single neurons within an otherwise normal culture alters the ability of cells to form synaptic connections. We generated two siRNA constructs (siRNA_EphB2.1 and siRNA_EphB2.2) against different regions of EphB2. These siRNAs specifically inhibited expression of EphB2 when cotransfected in HEK293T cells as well as expression of a YFP-tagged EphB2 construct in neurons (supplemental Fig. S1, available at www.jneurosci.org as supplemental material). We used siRNA_EphB2.1 for most of our experiments, but results were confirmed with siRNA_EphB2.2. We also generated a FLAG-tagged EphB2 mutant construct (fEphB2mut) by making silent mutations within the region targeted by siRNA_ EphB2.1, rendering fEphB2mut not susceptible to knockdown without altering the amino acid sequence of EphB2.

At 0 DIV, dissociated cortical neurons were transfected in suspension with GFP and either vector control (pSuper) (Brummelkamp et al., 2002) or siRNA_EphB2.1 using Lipofectamine 2000. At 9-11 DIV, neurons were fixed and immunostained with antibodies against GFP and SV2. Compared with vector control, we found that knockdown of EphB2 caused an approximate twofold decrease in the density of SV2-positive presynaptic contacts on the dendrites of transfected cells (Fig. $5 a, b$ ). This loss was rescued with cotransfection of fEphB2mut along with siRNA_ EphB2.1, indicating that the defect is specific to the absence of EphB2 signaling (Fig. 5a,b). These data demonstrate that EphB2 regulates the formation of certain presynaptic contacts onto individual cortical neurons. We also examined how knockdown of EphB2 in developing cells affected dendritic spine formation. Although spine density remains low in cultured neurons at this age in vitro, we detected a decrease in the presence of mature spines in dendrites of knockdown cells compared with control; this decrease was also rescued with coexpression of fEphB2mut (Fig. $5 c$ ). However, because the density of presynaptic puncta on these cells was far greater than the spine density, the decreased presence of SV2 clusters could not simply be attributable to the loss of spines.

Our data indicate that EphB2 signaling is involved in organizing both presynaptic and postsynaptic terminals in cultured neurons. We next evaluated whether knockdown of EphB2 causes an alteration in excitatory synaptic transmission. Cortical neurons were transfected in suspension at 0 DIV with GFP and vector control, siRNA_EphB2.1, or siRNA_EphB2.2. At 9-11 DIV, whole-cell patch-clamp recordings were made from transfected GFP-positive cells. We recorded miniature EPSCs (mEPSCs) from cells in each condition by blocking spontaneous action potentials with TTX and inhibitory currents with bicuculline and picrotoxin. Knockdown of EphB2 with siRNA_EphB2.1 caused a significant decrease in the frequency of excitatory events compared with vector control (knockdown, $1.20 \pm 0.26 \mathrm{~Hz}$; control, $0.23 \pm 0.12 \mathrm{~Hz}$ ), with no effect on mEPSC amplitude (knockdown, $11.97 \pm 0.16 \mathrm{pA}$; control, $12.23 \pm 0.49 \mathrm{pA}$ ) (Fig. $5 c-e$ ). siRNA_EphB2.2 resulted in similar changes (data not shown). In many knockdown cells, we recorded for an extended time period (2-3 min) without witnessing any spontaneous events. In all cases, the recorded events were abolished by application of AMPAR antagonist CNQX and NMDAR antagonist MK-801, indicating that they are glutamatergic synaptic inputs. Together, these results demonstrate that EphB2 is required for the forma- 
tion of functional excitatory synaptic connections between neurons during development.

\section{Reduced synapse density in early} postnatal mice lacking EphB1-EphB3 To test whether EphBs control synapse formation during development in vivo, we examined cortex from early postnatal animals lacking the three EphB subtypes expressed in brain (EphB1-EphB3). We fixed cortical cryosections from P4-P6 WT, $E p h B 1^{-1-}, 3^{-1-}$ or EphB1 $1^{-1-}, 2^{-/-}, 3^{-1-}$ mice with trichloroacetic acid and immunostained with presynaptic and postsynaptic marker proteins (Hayashi et al., 1999; Christopherson et al., 2005). As expected from work in $E p h B 2^{-1-}$ mice, there was a $\sim 35 \%$ reduction in $\mathrm{NR} 2 \mathrm{~B}$ puncta density in EphB triple-null animals. In contrast to the $E p h B 2^{-1-}$ mice in which there was no reported change in synapse number, we also observed an $\sim 25 \%$ decrease in SV2 puncta density and an $\sim 40 \%$ reduction in the density of NR2B-containing synapses, defined by colocalized SV2 and NR2B puncta, in triple knock-out animals compared with WT (Fig. $6 a-g$ ). The remaining SV2 and NR2B puncta in $E p h B 1^{-/-}, 2^{-/-}, 3^{-/-}$mice were colocalized at a percentage similar to WT, suggesting a specific change in synapse number as opposed to disruption of synaptic contacts (data not shown). Although the reduction in SV2 density alone is indicative of a loss of synapses in EphB1-EphB3 knock-out animals, we wanted to confirm this finding using specific markers of excitatory synapses. We double-labeled brain sections from WT, $E p h B 1^{-1-}, 3^{-/-}$, or EphB1 $1^{-/-}, 2^{-/-}, 3^{-/-}$mice with antibodies recognizing VGLUT1 and SynGAP, a glutamatergic postsynaptic signaling molecule that associates directly with PSD-95 (Kim et al., 1998). We found an $\sim 49 \%$ reduction in the density of colocalized VGLUT1/SynGAP puncta in EphB1 $1^{-/-}, 2^{-/-}, 3^{-/-}$brains compared with WT (Fig. $6 g-i$ ), demonstrating fewer excitatory synapses in these animals. Double knock-out animals lacking only EphB1 and EphB3 did not show a significant loss of synapse density with any of these antibodies (data not shown), indicating that the presence of EphB2 alone is sufficient for formation of normal numbers of synapses.

\section{Cell-autonomous regulation of PSD-95-GFP cluster} formation and localization in cortex of $\mathrm{EphB1}^{-/-}, 2^{-/-}, 3^{-/-}$mice

To further investigate the localization of synapses in $E p h B 1^{-/-}, 2^{-/-}, 3^{-/-}$mice and to determine whether there are fewer synapses per unit dendritic length, we cultured brain slices from $E p h B 1^{-/-}, 2^{-/-}, 3^{-/-}$animals and examined the number of postsynaptic specializations that formed on cortical pyramidal neurons. To label putative synaptic sites in living neurons, we took advantage of previous work demonstrating that a GFP-tagged PSD-95 expression construct labels excitatory synapses in brain slice (Craven et al., 1999; Qin et al., 2001). Brain slices were made from P4-P6 WT and EphB1 $1^{-/-}, 2^{-/-}, 3^{-/-}$mice and transfected using the biolistic method at $\sim 2$ DIV with PSD-95-GFP to mark synaptic sites and tdTomato (a red fluorescent protein) to allow visualization of dendritic morphology. Similar numbers of neurons expressed both constructs in slices from each animal genotype, with high levels of cotransfection $(>95 \%)$ and no apparent changes in transfected cell health, slice health, or total area per cell. Layer 2-3 or layer 5 cortical neurons in brain slices from WT or mutant animals were imaged blind to genotype 2-7 d after transfection, and the density of PSD-95-GFP puncta in tdTomato-labeled neurons was measured.

We found significantly fewer PSD-95-GFP puncta in slices cultured from EphB1 $1^{-1-}, 2^{-/-}, 3^{-/-}$mice compared with WT mice (Fig. $7 d$ ) and observed differences in the localization of remaining puncta for each group. In WT neurons, PSD-95-GFP clusters appeared throughout the dendritic arbor of transfected cells and could be visualized in numerous short, spine-like dendritic protrusions; approximately two-thirds of PSD-95-GFP puncta were found on dendritic protrusions, with the remainder localized to the dendritic shaft (Fig. 7a). Neurons in brain slice culture from animals lacking EphB1-EphB3 appeared markedly different, with PSD-95-GFP puncta still present but found primarily along dendritic shafts and rarely in dendritic protrusions (Fig. $7 b, f$ ). There was not a change in the density of PSD-95-GFP puncta located on the dendritic shaft in EphB1 $1^{-/-}, 2^{-1-}, 3^{-/-}$ mice compared with WT (Fig. 7e). Previous work has 

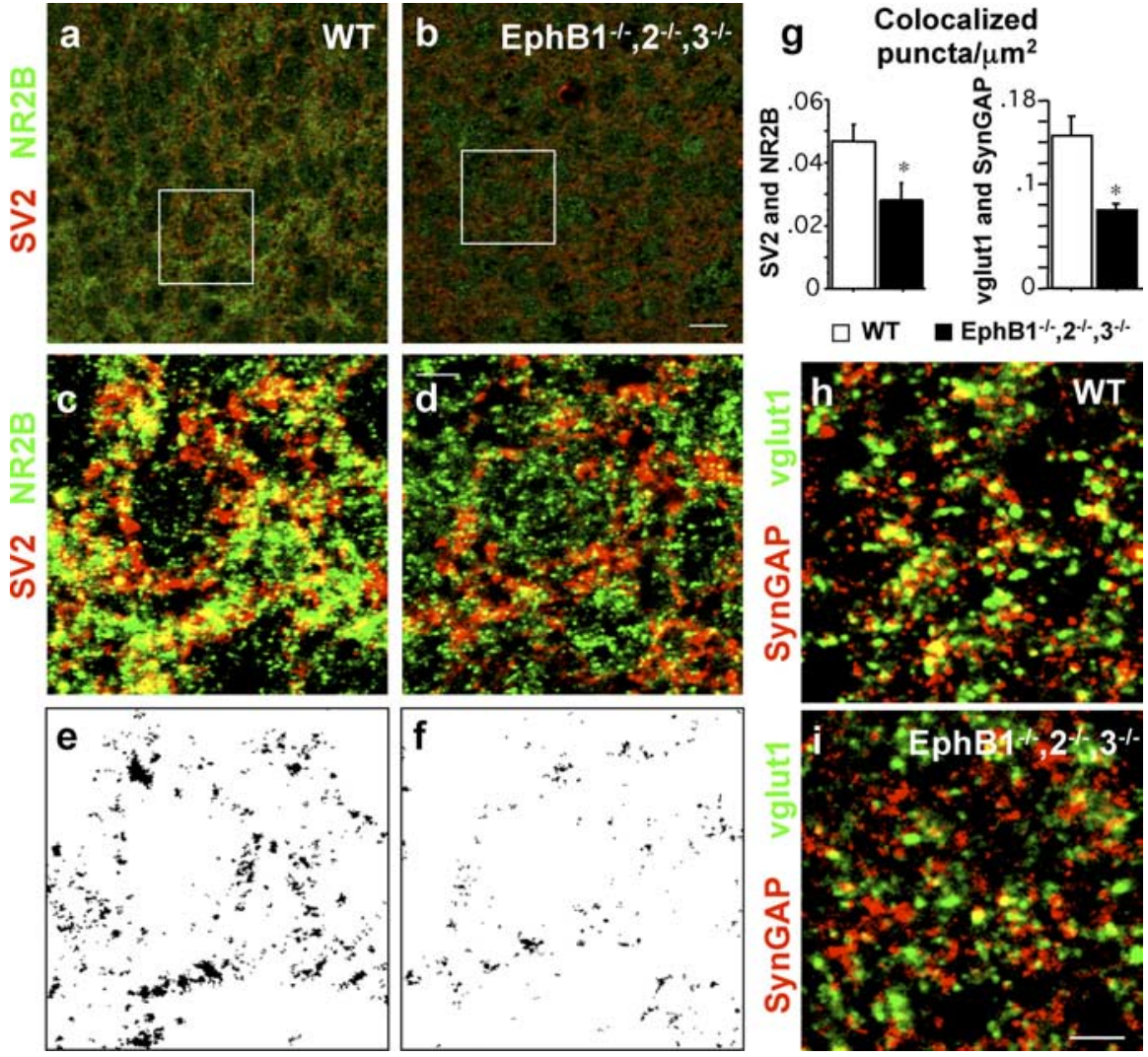

Figure 6. Reduced synapse density in cortex from early postnatal mice lacking EphB1-EphB3. $\boldsymbol{a}, \boldsymbol{b}$, Representative fields from layer 5 cortex immunostained with SV2 (red) and NR2B (green). Scale bar, $11 \mu \mathrm{m}$. $\boldsymbol{c}$, d, High-contrast magnification of boxed region from $\boldsymbol{a}$ and $\boldsymbol{b}$. Yellow indicates colocalization of SV2 and NR2B. Scale bar, $4 \mu \mathrm{m} . \boldsymbol{e}, \boldsymbol{f}$, Binary thresholded images of colocalized SV2 and NR2B areas from c and $\boldsymbol{d}$. $\boldsymbol{g}$, Quantification of density of colocalized puncta in cortical brain sections from P4-P6 WT ( $n=15$ fields, 3 animals) and EphB1 ${ }^{-1-}, 2^{-1-}, 3^{-/-}(n=20$ fields, 4 animals) mice. $\boldsymbol{h}$, $\boldsymbol{i}$, Representative highmagnification images of brain sections immunostained with VGLUT1 (green) and SynGAP (red). Yellow indicates colocalization. Scale bar, $3 \mu \mathrm{m}$. Error bars indicate SEM. * $p<0.05$.

demonstrated decreased spine density in brains of mature EphB1 $1^{-/-}, 2^{-/-}, 3^{-/-}$mice (Henkemeyer et al., 2003), and, in these early postnatal animals, we find an increased density of filopodial-like protrusions (M. B. Dalva, unpublished observations), often lacking PSD-95-GFP (Fig. 7b, arrowheads). These data suggest that, in brain slice, loss of EphB1-EphB3 results in the improper development and localization of synaptic specializations.

To investigate the specific role of EphB2 in postsynaptic specialization formation, we examined dendrites from cortical brain slices of double knock-out $E p h B 1^{-1-}, 3^{-/-}$mice. There were no differences in PSD-95-GFP density or localization compared with WT animals, indicating that the presence of EphB2 is sufficient to direct normal postsynaptic specialization formation (Fig. $7 d-f$ ). Defects in synapse formation in EphB1 $1^{-/-}, 2^{-/-}, 3^{-/-}$mice could be attributable to the global loss of EphB1-EphB3 from brain during development, by decreasing the density of contacting axons for example, or attributable to the specific absence of postsynaptic EphB in a single cell. To determine whether EphB2 acts cell autonomously during development to regulate the formation of excitatory synaptic specializations, we cotransfected fEphB2 with PSD-95-GFP into brains slices from $E p h B 1^{-/-}, 2^{-/-}, 3^{-/-}$mice at 2 DIV. Surprisingly, we found that postnatal reexpression of EphB2 in a single cell was sufficient to rescue the density, localization, and dendritic protrusion defects found in cortical neurons from $E p h B 1^{-/-}, 2^{-/-}, 3^{-/-}$ animals (Fig. $7 d-f$ ) (data not shown). These neurons appeared similar to WT pyramidal cells, with PSD-95-GFP puncta appearing on spine-like protrusions throughout the dendritic arbor (Fig. 7c). Thus, synapse abnormalities in EphB1 $1^{-/-}, 2^{-/-}, 3^{-/-}$mice are not attributable to nonspecific developmental defects, and EphB2 controls formation of normal postsynaptic specializations cell autonomously.

\section{Discussion}

Although EphB signaling has a clear role in dendritic spine morphogenesis and NMDAR clustering (Dalva et al., 2000; Ethell et al., 2001; Takasu et al., 2002; Henkemeyer et al., 2003; Penzes et al., 2003), the extent to which it acts as a regulator of glutamatergic synaptic connections has remained in doubt. Together with previous work, our data demonstrate that distinct protein-protein interaction and signaling domains of EphB2 are able to independently regulate the essential components of a mature excitatory synapse. We find that decreasing EphB expression reduces the number of synaptic inputs, and, using postnatal single-cell rescue in a mammalian transgenic system, we provide evidence that EphB2 acts cell autonomously to regulate synapse number and localization. These results establish that EphB has a fundamental role in the development of CNS excitatory synapses.

\section{EphB-dependent formation of mature glutamatergic synapses}

The proper complement and localization of NMDARs and AMPARs is required for experience-dependent modulation of synaptic strength at many excitatory synapses in the CNS (Bredt and Nicoll, 2003). We demonstrate that EphB2 is necessary for the development of many functional glutamatergic synapses and provide a mechanism by which EphB can regulate formation of mature postsynaptic terminals containing both NMDA and AMPA receptors. EphB also regulates the formation of dendritic spines through kinase domain activity. Interestingly, we show that the EphBdependent mechanisms that induce spine formation and synapse maturation are dissociable as neurons begin to form synapses. Without the kinase activity required for spine formation, EphB can still cluster with AMPARs; without its PDZ binding domain involved in local clustering with AMPARs, EphB can still regulate spinogenesis. In addition, EphB2 kinase activity is involved in a more global control of AMPAR clustering [likely via regulation of cell-wide endocytosis (Irie et al., 2005)] that is independent of these local protein-protein interactions. Our data therefore indicate that distinct domains of EphB2 control specific aspects of excitatory synapse development.

These results suggest two potential models for the function of EphB during synaptogenesis. EphB might initiate de novo formation of excitatory synapses, with the ephrinB/EphB/NMDAR complex serving as a nucleation point around which other necessary molecules accumulate via protein-protein interactions. 

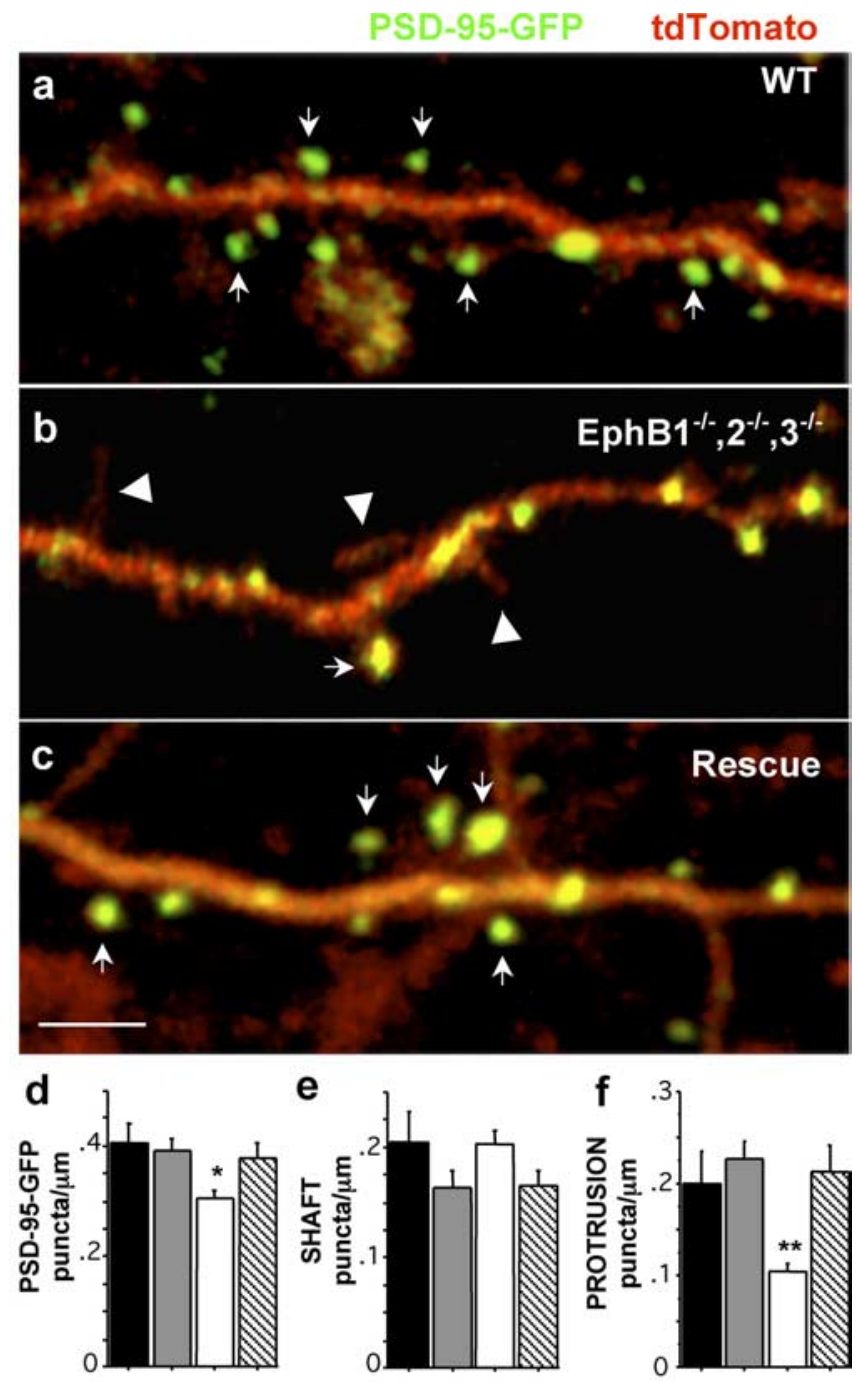

WT

EphB1 $1^{-1-}, 3^{-1-}$

EphB1 $1^{-1-}, 2^{-1-}, 3^{-1-}$

Rescue

Figure 7. Cell-autonomous regulation of postsynaptic specialization formation and localization in brain slices from $E p h B 1^{-1-}, 2^{-1-}, 3^{-/-}$mice. $\boldsymbol{a}, \boldsymbol{b}$, Representative dendrite from layer $2 / 3$ cortical pyramidal neuron of P5 WT or EphB1 $1^{-/-}, 2^{-/-}, 3^{-/-}$mouse, transfected 2 DIV with PSD-95-GFP and tdTomato. Arrows indicate PSD-95-GFP puncta localized to spine-like protrusions; arrowheads indicate tdTomato-labeled protrusions without PSD-95-GFP puncta. C, Representative dendrite from layer 2/3 cortical pyramidal neuron from P5 EphB1 $1^{-1-}, 2^{-/-}, 3^{-/-}$mouse, transfected 2 DIV with PSD-95-GFP, fEphB2, and tdTomato. Arrows indicate PSD-95-GFP puncta localized to spine-like protrusions. Scale bar, $4 \mu \mathrm{m}$. $\boldsymbol{d}$, Quantification of PSD-95-GFP per unit length (micrometers) in cortical neurons of brain slices cultured from WT ( $n=18$ neurons, 3 animals), EphB1 ${ }^{-/-}, 3^{-/-}$ ( $n=32$ neurons, 4 animals), EphB1 $1^{-/-}, 2^{-/-}, 3^{-/-}(n=51$ neurons, 7 animals), and rescue (EphB1 $1^{-1-}, 2^{-1-}, 3^{-/-}$plus fEphB2; $n=13$ neurons, 3 animals) mice. $E$, Quantification of dendritic shaft-localized PSD-95-GFP puncta density per unit length (micrometers). $\boldsymbol{f}$, Quantification of dendritic protrusion-localized PSD-95-GFP puncta density per unit length (micrometer). Error bars indicate SEM. ${ }^{*} p<0.05 ;{ }^{* *} p \leq 0.0005$.

Alternatively, EphB might traffic to preexisting NMDARcontaining synaptic sites organized by other synaptogenic molecules and act as a maturation factor to recruit AMPARs, induce spine formation, and modulate presynaptic function via transsynaptic signaling. Although additional work will be necessary to distinguish between these two models, the ability of EphB to associate with and modulate the function and/or localization of NMDARs and AMPARs, together with our knockdown data demonstrating fewer excitatory inputs without EphB2, suggests that the EphB signaling is intimately involved in glutamatergic synaptogenesis.

\section{EphB control of presynaptic differentiation}

An outstanding question regarding EphB-ephrinB signaling at synapses has been whether the interaction triggers presynaptic differentiation in addition to postsynaptic functions. We now provide the first direct evidence for trans-synaptic EphB signaling in presynaptic development using a heterologous cell coculture system and show that this interaction induces functional synaptic vesicle release. In contrast to the other known postsynaptic adhesion signals that drive presynaptic maturation [neuroligins (Scheiffele et al., 2000), SynCAMs (Biederer et al., 2002), and the recently identified NGL-2 (Kim et al., 2006), all of which contain PDZ binding domains that interact with PSD-95], EphB2 contains the PDZ binding domain sequence recognizing the GRIP/ PICK family of PDZ domain-containing proteins (Torres et al., 1998). A direct interaction with PSD-95, therefore, is not necessarily an obligatory feature of synaptogenic molecules. Although previous work has investigated whether EphB2 induces presynaptic specializations in coculture (Biederer et al., 2002), the study focused on changes in the size of the recycling vesicle pool and used a different cell type (hippocampus) than our system. Thus, differences between these published results and our findings might be attributable to variations in both the assay and analysis but could also reflect a specific role for $\mathrm{EphB}$ in initiating particular types of synaptic contacts.

Our data argue strongly that EphB2 can act as a trans-cellular signal during synaptogenesis. The most likely ligand of the postsynaptic EphB2 receptor is ephrinB, which we show in cortical cultures is enriched in axons and at synapses and which is recruited to appropriate "postsynaptic" EphB2 constructs expressed in HEK293T cells cocultured with neurons. The possibility remains that other molecules competent to bind the ephrin binding domain of EphB2 might be involved in the recruitment of presynaptic vesicles, although there are currently no other known ligands. Extensive work in hippocampus has revealed a complex expression pattern for ephrinBs, with both presynaptic and postsynaptic functions (Contractor et al., 2002; Henkemeyer et al., 2003; Palmer and Klein, 2003; Grunwald et al., 2004; Rodenas-Ruano et al., 2006). Determining what role ephrins play in the development of synaptic specializations will therefore be necessary for a more complete understanding of EphB-ephrinB signaling at the synapse.

Our coculture data also indicate that EphB2 is a more potent inducer of presynaptic specializations than EphA4, although both receptors can bind ephrinB ligands. Whether this result arises from differences in ephrinB subtype ligand affinity or in the specific axonal proteins that associate with each Eph will be important to resolve. One intriguing possibility is that the extracellular domain of EphB2 enables it to interact with proteins in addition to ephrinB and the NMDA receptor that act to promote presynaptic maturation.

\section{Electrophysiological evidence for EphB control of synapse formation}

Knockdown of EphB2 results in reduced frequency but not amplitude of spontaneous miniature excitatory synaptic currents. Together with our observation that knockdown of EphB2 causes a reduction in the density of presynaptic SV2 clusters, our data demonstrate that decreased EphB2 expression in cultured cortical neurons causes a loss in the number of functional synaptic inputs. The absence of a change in mEPSC amplitude after EphB2 
knockdown indicates that those synapses remaining are unaffected and suggests that EphB is essential for the formation of a specific subset of synaptic contacts onto a cell.

Although in vivo loss of EphB1-EphB3 is required to observe changes in synapse number (Grunwald et al., 2001; Henderson et al., 2001; Henkemeyer et al., 2003), in vitro knockdown of EphB2 alone is sufficient to reduce synapse density. This difference between in vitro and in vivo results is not surprising: Knockdown of PSD-95 or the neuroligins in vitro has large effects on synapse number that are not phenocopied with knock-out in vivo (Gerrow et al., 2006; Varoqueaux et al., 2006), and knock-out of EphB1-EphB3 has more severe effects in vitro than in vivo (Henkemeyer et al., 2003). One likely possibility is that cultured neurons cannot compensate for loss of synaptogenic molecules in the same manner as within an animal. Continued work in vivo will be necessary to fully understand the role of EphBs and other synaptogenic signals in animals during development.

\section{Role of EphB in synapse formation in mice lacking EphB1-EphB3}

In cultured brain slices from $E p h B 1^{-1-}, 2^{-/-}, 3^{-/-}$mice, we find reduced overall numbers of PSD-95 puncta and a specific loss of puncta in dendritic protrusions. Importantly, shaft puncta remain at WT levels in mice lacking EphB1-EphB3. We also show, in contrast to recent findings in animals lacking the neuroligin subtypes expressed in brain (Varoqueaux et al., 2006), that the absence of EphB1-EphB3 causes a decrease in excitatory synapse number in cortex. Given the involvement of EphBs in axon guidance during development, defects in synapse formation in EphB1 ${ }^{-1-}, 2^{-/-}, 3^{-/-}$mice might be expected because of fewer available presynaptic inputs or mistargeting of axons to inappropriate brain areas. Remarkably, postnatal reexpression of EphB2 within individual neurons from animals lacking EphB1-EphB3 is sufficient to restore postsynaptic specializations to WT levels, suggesting that the loss of EphBs results in specific defects in synapse formation. This is the first demonstration of a synaptogenic factor that can function cell autonomously within a more complex cellular environment. However, EphB signaling cannot be essential for the formation of all excitatory inputs, because $E p h B 1^{-1-}, 2^{-1-}, 3^{-/-}$mice remain viable. Rather, EphB appears to play a critical role in the establishment of only particular types of glutamatergic contacts.

Our work in vitro indicates that postsynaptically localized EphB2 can control organization of certain presynaptic and postsynaptic specializations and the formation of dendritic spines through functionally independent domains. Determining whether abnormal dendritic morphologies and defective synapse formation in developing EphB1 $1^{-/-}, 2^{-/-}, 3^{-/-}$mice result directly from one another or are caused by the loss of independent EphB signals will require a detailed structure/function approach in brain slice. Regardless, this study suggests that EphB preferentially regulates the development and maturation of a specific class of excitatory synapses: those that form on dendritic spines. Thus, even within a single cell, multiple pathways orchestrate the formation of different synaptic contacts. These findings emphasize the complex interactions between particular gene families that must be coordinated to regulate excitatory synaptogenesis.

\section{References}

Biederer T, Sara Y, Mozhayeva M, Atasoy D, Liu X, Kavalali ET, Sudhof TC (2002) SynCAM, a synaptic adhesion molecule that drives synapse assembly. Science 297:1525-1531.

Bredt DS, Nicoll RA (2003) AMPA receptor trafficking at excitatory synapses. Neuron 40:361-379.
Brummelkamp TR, Bernards R, Agami R (2002) A system for stable expression of short interfering RNAs in mammalian cells. Science 296:550-553.

Christopherson KS, Ullian EM, Stokes CC, Mullowney CE, Hell JW, Agah A, Lawler J, Mosher DF, Bornstein P, Barres BA (2005) Thrombospondins are astrocyte-secreted proteins that promote CNS synaptogenesis. Cell 120:421-433.

Contractor A, Rogers C, Maron C, Henkemeyer M, Swanson GT, Heinemann SF (2002) Trans-synaptic Eph receptor-ephrin signaling in hippocampal mossy fiber LTP. Science 296:1864-1869.

Craig AM, Graf ER, Linhoff MW (2006) How to build a central synapse: clues from cell culture. Trends Neurosci 29:8-20.

Craven SE, El-Husseini AE, Bredt DS (1999) Synaptic targeting of the postsynaptic density protein PSD-95 mediated by lipid and protein motifs. Neuron 22:497-509.

Dalva MB, Takasu MA, Lin MZ, Shamah SM, Hu L, Gale NW, Greenberg ME (2000) EphB receptors interact with NMDA receptors and regulate excitatory synapse formation. Cell 103:945-956.

Ehlers MD (2000) Reinsertion or degradation of AMPA receptors determined by activity-dependent endocytic sorting. Neuron 28:511-525.

Ethell IM, Irie F, Kalo MS, Couchman JR, Pasquale EB, Yamaguchi Y (2001) EphB/syndecan-2 signaling in dendritic spine morphogenesis. Neuron 31:1001-1013.

Flanagan JG, Vanderhaeghen P (1998) The ephrins and Eph receptors in neural development. Annu Rev Neurosci 21:309-345.

Gerrow K, Romorini S, Nabi SM, Colicos MA, Sala C, El-Husseini A (2006) A preformed complex of postsynaptic proteins is involved in excitatory synapse development. Neuron 49:547-562.

Graf ER, Zhang X, Jin SX, Linhoff MW, Craig AM (2004) Neurexins induce differentiation of GABA and glutamate postsynaptic specializations via neuroligins. Cell 119:1013-1026.

Grunwald IC, Korte M, Wolfer D, Wilkinson GA, Unsicker K, Lipp HP, Bonhoeffer T, Klein R (2001) Kinase-independent requirement of EphB2 receptors in hippocampal synaptic plasticity. Neuron 32:1027-1040.

Grunwald IC, Korte M, Adelmann G, Plueck A, Kullander K, Adams RH, Frotscher M, Bonhoeffer T, Klein R (2004) Hippocampal plasticity requires postsynaptic ephrinBs. Nat Neurosci 7:33-40.

Hayashi K, Yonemura S, Matsui T, Tsukita S (1999) Immunofluorescence detection of ezrin/radixin/moesin (ERM) proteins with their carboxylterminal threonine phosphorylated in cultured cells and tissues. J Cell Sci 112:1149-1158.

Henderson JT, Georgiou J, Jia Z, Robertson J, Elowe S, Roder JC, Pawson T (2001) The receptor tyrosine kinase EphB2 regulates NMDA-dependent synaptic function. Neuron 32:1041-1056.

Henkemeyer M, Itkis OS, Ngo M, Hickmott PW, Ethell IM (2003) Multiple EphB receptor tyrosine kinases shape dendritic spines in the hippocampus. J Cell Biol 163:1313-1326.

Hoogenraad CC, Milstein AD, Ethell IM, Henkemeyer M, Sheng M (2005) GRIP1 controls dendrite morphogenesis by regulating EphB receptor trafficking. Nat Neurosci 8:906-915.

Irie F, Okuno M, Pasquale EB, Yamaguchi Y (2005) EphrinB-EphB signalling regulates clathrin-mediated endocytosis through tyrosine phosphorylation of synaptojanin 1. Nat Cell Biol 7:501-509.

Kayser MS, Dalva MB (2006) Synaptogenesis. In: Textbook of neural repair and rehabilitation (Selzer ME, Cohen LG, Gage FH, Clarke S, Duncan PW, eds). Cambridge, UK: Cambridge UP.

Kim JH, Liao D, Lau LF, Huganir RL (1998) SynGAP: a synaptic RasGAP that associates with the PSD-95/SAP90 protein family. Neuron 20:683-691.

Kim S, Burette A, Chung HS, Kwon SK, Woo J, Lee HW, Kim K, Kim H, Weinberg RJ, Kim E (2006) NGL family PSD-95-interacting adhesion molecules regulate excitatory synapse formation. Nat Neurosci 9:1294-1301.

Ko J, Kim S, Chung HS, Kim K, Han K, Kim H, Jun H, Kaang BK, Kim E (2006) SALM synaptic cell adhesion-like molecules regulate the differentiation of excitatory synapses. Neuron 50:233-245.

Krueger SR, Kolar A, Fitzsimonds RM (2003) The presynaptic release apparatus is functional in the absence of dendritic contact and highly mobile within isolated axons. Neuron 40:945-957.

Li Z, Sheng M (2003) Some assembly required: the development of neuronal synapses. Nat Rev Mol Cell Biol 4:833-841. 
Lo DC, McAllister AK, Katz LC (1994) Neuronal transfection in brain slices using particle-mediated gene transfer. Neuron 13:1263-1268.

McAllister AK (2004) Biolistic transfection of cultured organotypic brain slices. Methods Mol Biol 245:197-206.

O’Brien RJ, Mammen AL, Blackshaw S, Ehlers MD, Rothstein JD, Huganir RL (1997) The development of excitatory synapses in cultured spinal neurons. J Neurosci 17:7339-7350.

Palmer A, Klein R (2003) Multiple roles of ephrins in morphogenesis, neuronal networking, and brain function. Genes Dev 17:1429-1450.

Papa M, Bundman MC, Greenberger V, Segal M (1995) Morphological analysis of dendritic spine development in primary cultures of hippocampal neurons. J Neurosci 15:1-11.

Penzes P, Beeser A, Chernoff J, Schiller MR, Eipper BA, Mains RE, Huganir RL (2003) Rapid induction of dendritic spine morphogenesis by transsynaptic ephrinB-EphB receptor activation of the Rho-GEF kalirin. Neuron 37:263-274.

Qin L, Marrs GS, McKim R, Dailey ME (2001) Hippocampal mossy fibers induce assembly and clustering of PSD95-containing postsynaptic densities independent of glutamate receptor activation. J Comp Neurol 440:284-298.

Rodenas-Ruano A, Perez-Pinzon MA, Green EJ, Henkemeyer M, Liebl DJ (2006) Distinct roles for ephrinB3 in the formation and function of hippocampal synapses. Dev Biol 292:34-45.

Scheiffele P (2003) Cell-cell signaling during synapse formation in the CNS. Annu Rev Neurosci 26:485-508.
Scheiffele P, Fan J, Choih J, Fetter R, Serafini T (2000) Neuroligin expressed in nonneuronal cells triggers presynaptic development in contacting axons. Cell 101:657-669.

Song I, Huganir RL (2002) Regulation of AMPA receptors during synaptic plasticity. Trends Neurosci 25:578-588.

Takasu MA, Dalva MB, Zigmond RE, Greenberg ME (2002) Modulation of NMDA receptor-dependent calcium influx and gene expression through EphB receptors. Science 295:491-495.

Torres R, Firestein BL, Dong H, Staudinger J, Olson EN, Huganir RL, Bredt DS, Gale NW, Yancopoulos GD (1998) PDZ proteins bind, cluster, and synaptically colocalize with Eph receptors and their ephrin ligands. Neuron 21:1453-1463.

Varoqueaux F, Aramuni G, Rawson RL, Mohrmann R, Missler M, Gottmann K, Zhang W, Sudhof TC, Brose N (2006) Neuroligins determine synapse maturation and function. Neuron 51:741-754.

Washbourne P, Dityatev A, Scheiffele P, Biederer T, Weiner JA, Christopherson KS, El-Husseini A (2004) Cell adhesion molecules in synapse formation. J Neurosci 24:9244-9249.

Xia Z, Dudek H, Miranti CK, Greenberg ME (1996) Calcium influx via the NMDA receptor induces immediate early gene transcription by a MAP kinase/ERK-dependent mechanism. J Neurosci 16:5425-5436.

Xu Q, Mellitzer G, Robinson V, Wilkinson DG (1999) In vivo cell sorting in complementary segmental domains mediated by Eph receptors and ephrins. Nature 399:267-271. 